\title{
1 Reactions of aliphatic amines with ozone: Kinetics and mechanisms
}

2 Sungeun Lim ${ }^{1,2}$, Christa S. McArdell ${ }^{1}$, Urs von Gunten ${ }^{1,2^{*}}$

$3{ }^{1}$ Eawag, Swiss Federal Institute of Aquatic Science and Technology, Ueberlandstrasse 133, 8600

4 Duebendorf, Switzerland

$5{ }^{2}$ School of Architecture, Civil and Environmental Engineering (ENAC), École Polytechnique Fédérale de

6 Lausanne (EPFL), 1015 Lausanne, Switzerland

$7 \quad{ }^{*}$ Corresponding author: vongunten@eawag.ch, phone: +4158765 5270

This document is the accepted manuscript version of the following article:

Lim, S., McArde11, C. S., \& von Gunten, U. (2019). Reactions of aliphatic amines with ozone: kinetics and mechanisms. Water Research, 157, 514-528.

https://doi.org/10.1016/j.watres.2019.03.089

This manuscript version is made available under the CC-BY-NC-ND 4.0

1icense http://creativecommons.org/1icenses/by-nc-nd/4.0/ 
8

\section{Abstract}

Aliphatic amines are common constituents in micropollutants and dissolved organic matter and present in elevated concentrations in wastewater-impacted source waters. Due to high reactivity, reactions of aliphatic amines with ozone are likely to occur during ozonation in water and wastewater treatment. We investigated the kinetics and mechanisms of the reactions of ozone with ethylamine, diethylamine, and triethylamine as model nitrogenous compounds. Species-specific second-order rate constants for the neutral parent amines ranged from $9.3 \times 10^{4}$ to $2.2 \times 10^{6} \mathrm{M}^{-1} \mathrm{~s}^{-1}$ and the apparent second-order rate constants at $\mathrm{pH} 7$ for potential or identified transformation products were $6.8 \times 10^{5} \mathrm{M}^{-1} \mathrm{~s}^{-1}$ for $\mathrm{N}, \mathrm{N}$ diethylhydroxylamine, $\sim 10^{5} \mathrm{M}^{-1} \mathrm{~s}^{-1}$ for $N$-ethylhydroxylamine, $1.9 \times 10^{3} \mathrm{M}^{-1} \mathrm{~s}^{-1}$ for $N$-ethylethanimine oxide, and 3.4 $\mathrm{M}^{-1} \mathrm{~s}^{-1}$ for nitroethane. Product analyses revealed that all amines were transformed to products containing a nitrogen-oxygen bond (e.g., triethylamine $N$-oxide and nitroethane) with high yields, i.e., 64 $-100 \%$ with regard to the abated target amines. These findings could be confirmed by measurements of singlet oxygen and hydroxyl radical which are formed during the amine-ozone reactions. Based on the high yields of nitroethane from ethylamine and diethylamine, a significant formation of nitroalkanes can be expected during ozonation of waters containing high levels of dissolved organic nitrogen, as expected in wastewaters or wastewater-impaired source waters. This may pose adverse effects on the aquatic environment and human health.

Keywords: aliphatic amines; ozone; reaction kinetics; reaction mechanisms; transformation products; nitroalkanes 


\section{Introduction}

Ozone has been used as a disinfectant and/or oxidant in water and wastewater treatment since the early $20^{\text {th }}$ century (von Sonntag and von Gunten, 2012). It has a significant potential for the abatement of micropollutants in drinking waters and also recently in wastewater effluents (Eggen et al., 2014; Tentscher et al., 2018; Ternes et al., 2003; von Gunten, 2018). In general, ozonation reduces the overall toxicity exerted by micropollutants by eliminating or altering the moieties responsible for biological activities (Dodd et al., 2009; Lee et al., 2008; Mestankova et al., 2011). However, an increased toxicity has also been observed in ozone-treated waters (Magdeburg et al., 2014; Stalter et al., 2010; von Gunten, 2018). This resulted mainly from the reaction of ozone with dissolved organic matter (DOM), thereby forming byproducts such as quinones (Tentscher et al., 2018), low molecular weight organic carbon compounds (Hammes et al., 2006; Ramseier et al., 2011), and compounds containing nitrogenoxygen bonds (McCurry et al., 2016). Micropollutants can also be transformed to toxic transformation products upon ozonation, but their contribution to the overall toxicity is expected to be smaller, as DOM is present in much higher concentrations than micropollutants in real water matrices and consumes by

42 far the largest fraction of the oxidants (von Gunten, 2018). Toxic oxygen-containing products, whether

43 they are byproducts from DOM or transformation products from micropollutants, are typically expected 44 to be removed by biological post-treatment (Hammes et al., 2006). However, some products (e.g., $N$ oxides) are persistent even during a biological post-treatment step (Bourgin et al., 2018; Hübner et al., 2015). To better understand the formation of persistent transformation products or byproducts, many

47 studies have been conducted to reveal their formation pathways (Krasner et al., 2013; Shah and Mitch, 48 2012) and to identify transformation products (Hübner et al., 2015; von Sonntag and von Gunten, 2012).

49 Recently, computational tools have been developed based on the current kinetic/mechanistic

50 knowledge to predict ozone exposure, reaction kinetics, and transformation products upon ozonation

51 (Lee et al., 2017; Lee and von Gunten, 2016). A successful implementation of such prediction tools will 
52 depend on the quality of the underlying reaction mechanisms which ideally cover a comprehensive

53 compilation of ozone-reactive moieties. A considerable wealth of information is available for the

54 reactions of ozone with ozone-reactive moieties such as olefins, aromatic compounds, and sulfur-

55 containing compounds, and the relevant information is also well documented (von Gunten, 2018; von

56 Sonntag and von Gunten, 2012). However, there is less information on the ozone-reactivity of

57 nitrogenous compounds and a need for a more fundamental understanding of the corresponding

58 reaction mechanisms.

59 Aliphatic amines, one of the simplest forms of nitrogen-containing compounds, are common

60 constituents of dissolved organic nitrogen (DON) (Westerhoff and Mash, 2002). Understanding the

61 reactions of aliphatic amines with ozone has been important, because, due to water scarcity, water

62 suppliers increasingly use impaired water resources with higher levels of DON. Such sources are surface

63 waters impacted by wastewater discharge, agricultural activities, or algal blooms (Graeber et al., 2015;

64 Pehlivanoglu-Mantas and Sedlak, 2006; Westerhoff and Mash, 2002) and wastewater effluents treated

65 for the purpose of direct potable reuse (Leverenz et al., 2011). Aliphatic amines are also commonly

66 found as functional groups in many organic micropollutants. From a list of 550 environmentally relevant

67 substances (Bourgin et al., 2018), more than $80 \%$ of micropollutants contain a nitrogen and about a

68 quarter of the nitrogen-containing micropollutants are categorized as aliphatic amines. Aliphatic amines

69 in their neutral forms react fast with ozone due to the lone electron pair on the nitrogen atom

70 susceptible to an electrophilic attack by ozone with second-order rate constants $k_{03}=10^{3}-10^{7} \mathrm{M}^{-1} \mathrm{~s}^{-1}$

71 (von Sonntag and von Gunten, 2012). Certain primary and secondary amines have the potential to be

72 transformed to harmful products such as $N$-nitrosodimethylamine with low yields of less than $0.02 \%$

73 upon ozonation (Andrzejewski et al., 2008; Yang et al., 2009) and chloropicrin with 50 \% yield upon

74 ozonation followed by post-chlorination (McCurry et al., 2016). These nitrogenous disinfection

75 byproducts (e.g., $N$-nitrosamines, halonitroalkanes) are significantly more toxic than regulated 
disinfection byproducts (e.g., trihalomethanes, haloacetic acids), wherefore the formation of the

77 nitrogenous disinfection byproducts has gained increasing attention recently (Bond et al., 2012, 2011;

78 Shah and Mitch, 2012). Despite the great relevance of aliphatic amines to the ozone chemistry in water

79 and wastewater treatment (common moieties, high reactivity towards ozone, potential of harmful

80 products), their reactions with ozone have not been entirely elucidated. In-depth investigations on

81 ozone-amine reactions were reported by Bailey in 1960s - 1970s but most experiments were carried out

82 in organic solvents (Bailey and Keller, 1968; Bailey et al., 1978). Current knowledge on amine-ozone

83 reactions in aqueous solutions is mostly limited to tertiary amines. $N$-oxides have often been detected

84 as major products during ozonation of micropollutants containing a tertiary amine moiety (Borowska et

85 al., 2016; Knoop et al., 2018; Lange et al., 2006; Lester et al., 2013; Muñoz and von Sonntag, 2000a;

86 Zimmermann et al., 2012). Accordingly, the principal mechanism of the reaction of tertiary amines with

87 ozone has been proposed as an oxygen transfer reaction where ozone initially attacks a tertiary amine nitrogen to form a $-\mathrm{N}^{+}-\mathrm{O}-\mathrm{O}-\mathrm{O}^{-}$adduct which further dissociates into a $\mathrm{N}$-oxide and singlet oxygen (von Sonntag and von Gunten, 2012). Alternatively, tertiary amines can react with ozone via an electron transfer pathway to yield an aminyl radical cation and an ozonide radical anion. The ensuing radicals further dissociate into a $\mathrm{N}$-dealkylated amine and a hydroxyl radical, respectively (von Sonntag and von

92 Gunten, 2012). For the reaction of secondary amines with ozone, hydroxylamines (an analogous product

93 to $\mathrm{N}$-oxides for tertiary amines) and primary amines were identified as products, but there is only

94 limited molar yield information (Benner and Ternes, 2009a, 2009b; Tekle-Röttering et al., 2016; von

95 Gunten, 2003). For the reaction of primary amines with ozone, nitrate and ammonia were identified as

96 final products (Berger et al., 1999; de Vera et al., 2017; Le Lacheur and Glaze, 1996), but the studies

97 were conducted under ozone excess conditions and the initial ozonation products of primary amines are 98 still unknown. 
The aim of this study was to investigate the chemistry of the ozone-amine reactions for simple aliphatic

100

101

102 amines such as ethylamine, diethylamine, and triethylamine. The second-order rate constants for the reactions of the model compounds with ozone, transformation products and reactive oxygen species (singlet oxygen and hydroxyl radical) were determined by various experimental approaches and analytical methods. In addition, kinetic experiments/simulations and quantum chemical computations were performed. Based on these results, reaction mechanisms for primary, secondary and tertiary amines were proposed, allowing a comprehensive assessment of the fate of these moieties during ozonation.

\section{Materials and Methods}

Chemical reagents. Chemicals and suppliers are listed in Table S1 in the supporting information. $N$ ethylethanimine oxide was synthesized at Eawag (Text S1) and UV-vis spectra of this compound were recorded as received $\left(\lambda_{\max }=224 \mathrm{~nm}\right)$. Working stocks of $N$-ethylethanimine oxide were freshly made every day and the concentrations were determined based on the absorbance at $224 \mathrm{~nm}$ (Figure S1).

Ozonation experiments. Ozone stock solutions were prepared by sparging ozone-containing oxygen through ultrapure water kept on ice (Bader and Hoigné, 1981). The concentration of ozone in the stock solution $(1.3-1.5 \mathrm{mM})$ was determined spectrophotometrically based on the molar absorption coefficient of ozone, $\varepsilon=3200 \mathrm{M}^{-1} \mathrm{~cm}^{-1}$ at $260 \mathrm{~nm}$ (von Sonntag and von Gunten, 2012). An aliquot of the ozone stock solution was added to the solution containing the target amine compound to initiate the ozone reaction with doses ranging from $0-300 \mu \mathrm{M}$. The solutions of the model compounds (ethylamine, diethylamine, $\mathrm{N}, \mathrm{N}$-diethylhydroxylamine, $\mathrm{N}$-ethylethanimine oxide, or triethylamine; initial concentrations $\sim 100 \mu \mathrm{M}$ ) were prepared in $10 \mathrm{mM}$ phosphate buffer at $\mathrm{pH} 7.50 \mathrm{mM}$ of $t$-butanol was present in the solutions as a hydroxyl radical scavenger to suppress unwanted side reactions associated with hydroxyl radical. The ozonated samples were typically allowed to react for 24 hours at room 
122 temperature to ensure a complete consumption of ozone and stored at $4^{\circ} \mathrm{C}$ for less than a week prior to

123 further analyses.

124 Reaction kinetics. Second-order rate constants for the reactions of the model compounds and their 125 transformation products with ozone in the $\mathrm{pH}$ range far below the $\mathrm{p} K_{\mathrm{a}}$ of the amines were determined 126 by a direct measurement of the ozone decrease with the indigo reagent (Text S2) (Bader and Hoigné, 127 1981). Under these conditions, the amines were predominantly present in the protonated form, which 128 lowered the reaction kinetics sufficiently to allow measurements by a direct method. The species129 specific second-order rate constants for the neutral amines were then obtained by extrapolating the 130 determined apparent second-order rate constants to a higher pH (Hoigné and Bader, 1983). Additionally, 131 a competition kinetic method with cinnamic acid as a competitor (Leitzke et al., 2001) was used for 132 determining apparent second-order rate constants of $\mathrm{N}, \mathrm{N}$-diethylhydroxylamine at $\mathrm{pH} 5-8$, which are 133 too high to be determined by the direct method.

134 Analytical methods. Diethylamine, $\mathrm{N}$-ethylethanimine oxide, triethylamine, triethylamine $\mathrm{N}$-oxide were 135 analyzed by liquid chromatography coupled with high resolution tandem mass spectrometry (LC136 HRMS/MS) and nitroethane was analyzed by GC-MS. Ethylamine was derivatized with 9-

137 fluorenylmethylchloroformate and the derivatized product was analyzed by HPLC-UV (Jámbor and 138 Molnár-Perl, 2009). Nitrite and nitrate were determined by ion chromatography with conductivity 139 detection. All chromatographic conditions and detection methods including the limits of quantification 140 and the measuring ranges are provided in detail in Text S3 and Table S2. Singlet oxygen was quantified 141 by a near-infrared photomultiplier tube which directly measured a characteristic phosphorescence of 142 singlet oxygen emitted at $1270 \mathrm{~nm}$. The setup and the reference reaction to calibrate the instrument 143 were adapted from a previous study (Muñoz et al., 2001) and described in Text S4. Hydroxyl radicals 144 were indirectly quantified by measuring the concentration of formaldehyde, a known product of the 
reaction of hydroxyl radicals with $t$-butanol (Flyunt et al., 2003; Nöthe et al., 2009). Formaldehyde was

146 quantified by derivatization with 2,4-dinitrophenylhydrazine followed by HPLC-UV analysis (Text S5)

147 (Lipari and Swarin, 1982). Hydrogen peroxide was indirectly quantified by measuring singlet oxygen

148 formation after adding hypochlorous acid to the samples containing hydrogen peroxide (Text S6)

149 (Tentscher et al., 2018).

150 Quantum chemical computations. All computations were conducted by the Gaussian 09 program

151 (Revision D.01) (Frisch et al., 2016). Gas phase electronic energies of all molecules were computed by

152 the $\operatorname{CCSD}(T)$ functional (Raghavachari et al., 1989) with the jul-cc-pVTZ basis set (Papajak et al., 2011).

153 Aqueous Gibbs free energies were calculated by adding gas phase thermal corrections (computed by

154 B3LYP/CBSB7) (Becke, 1993; Montgomery et al., 1999) and solvation effects (by M062X/6-31G*)

155 (Hariharan and Pople, 1973; Marenich et al., 2009; Zhao and Truhlar, 2008) to the gas phase electronic

156 energies. More details are provided in Text S8.

\section{3. Results and discussion}

158 The mechanisms for the reactions of ozone with aliphatic amines were elucidated as follows: (1)

159 Determination of apparent and species-specific second order rate constants for the reactions of the

160 selected amines with ozone, (2) identification/quantification of transformation products and (3) reactive

161 oxygen species $\left({ }^{1} \mathrm{O}_{2}\right.$ and $\left.\bullet \mathrm{OH}\right)$ formed during the amine-ozone reactions, (4) quantum chemical

162 computations, and (5) kinetic simulations. In the following these aspects are discussed and compiled to

163 overall proposed reaction mechanisms.

\subsection{Ozone kinetics}

Apparent second-order rate constants for the reactions of ethylamine, diethylamine, and triethylamine

166 with ozone were determined in the $\mathrm{pH}$ range $3-7$. Based on this, the species-specific second-order rate 
constants were calculated and are summarized in Table 1. The species-specific second-order rate

168 constants for the reactions of ozone with the neutral amines are in the range of $9.3 \times 10^{4}-2.2 \times 10^{6} \mathrm{M}^{-}$

$169{ }^{1} \mathrm{~s}^{-1}$. They are comparable to literature values within a factor of 2.6 , an acceptable deviation commonly

170 found among kinetic studies. At pH 7, the apparent second-order rate constants $\left(k_{\mathrm{obs}, \mathrm{pH}}\right)$ for the ozone

171 reactions with all amines were $3-4$ orders of magnitude lower because the protonated amines $\left(p K_{a}\right.$

172 values $10.5-11.0$ ) which are dominant at $\mathrm{pH} 7$, are practically unreactive with ozone. The second-order

173 rate constants for the reactions of potential or identified transformation products were also determined.

$174 \mathrm{~N}, \mathrm{~N}$-diethylhydroxylamine, a potential product from the diethylamine-ozone reaction, was very reactive

175 at $\mathrm{pH} 7$ due to its lower $\mathrm{p}_{\mathrm{a}}(5.4$, see below) compared to other amines, which leads to an almost $100 \%$

176 fraction of the neutral amine species at this $\mathrm{pH}$. The $\mathrm{p} K_{\mathrm{a}}$ of $\mathrm{N}, \mathrm{N}$-diethylhydroxylamine was estimated by

177 fitting the apparent second-order rate constants determined in the $\mathrm{pH}$ range $1.6-8.0$ to an expression

178 for the species-specific second-order rate constant. This includes the degree of dissociation of the amine

179 at a given $\mathrm{pH}$ and the corresponding species-specific rate constants, i.e., $k=k_{\mathrm{NH}+}(1-\alpha)+k_{\mathrm{N}} \alpha$ and $\alpha=1 /(1$

$\left.180+10^{\mathrm{pKa}-\mathrm{pH}}\right)$, where $k_{\mathrm{NH}+}$ and $k_{\mathrm{N}}$ are the species-specific second-order rate constants for the protonated

181 and the neutral amines, respectively, and $\alpha$ is the fraction of the neutral amine. As a result of the fitting

182 (shown in Figure S2), the estimated $\mathrm{p} K_{\mathrm{a}}$ value is 5.4 , similar to the predicted value of 5.7 determined by

183 a commercial $p K_{\mathrm{a}}$ prediction software (ACD/Labs, V 11.02) (https://www.acdlabs.com). The species-

184 specific second-order rate constant of $N, N$-diethylhydroxylamine was estimated as $7.0 \times 10^{5} \mathrm{M}^{-1} \mathrm{~s}^{-1} . \mathrm{N}$ -

185 ethylhydroxylamine, a potential product from the ethylamine-ozone reaction, was also very reactive at

$186 \mathrm{pH}$ 7. The estimated apparent second-order rate constant at $\mathrm{pH} 7\left(k_{\mathrm{obs}, \mathrm{pH} 7}\right)$ was $\sim 10^{5} \mathrm{M}^{-1} \mathrm{~s}^{-1}$, based on the

187 measured apparent second-order rate constants at $\mathrm{pH} 2$ and 4 and a predicted $\mathrm{p} K_{\mathrm{a}}$ value of 6.2

188 (ACD/Labs, $\mathrm{V}$ 11.02). The $k_{\mathrm{obs}, \mathrm{pH} 7}$ is only a rough estimate because only two $\mathrm{pH}$ conditions were applied.

189 The reaction kinetics of $N$-ethylethanimine oxide, an identified product from the reactions of

190 diethylamine and triethylamine with ozone, was determined with a fresh $N$-ethylethanimine oxide 
191 solution prepared in situ to minimize the impact of dimers on the reaction kinetics (Text S2). N-

192 ethylethanimine oxide was moderately reactive to ozone at $\mathrm{pH} 7$ with an apparent second-order rate 193 constant at $\mathrm{pH} 7, k_{\mathrm{obs}, \mathrm{pH} 7}=1.9 \times 10^{3} \mathrm{M}^{-1} \mathrm{~s}^{-1}$. Nitroethane, identified as a final product from all amine-

194 ozone reactions, reacted slowly with ozone with an apparent second-order rate constant at pH 7, $k_{\mathrm{obs}, \mathrm{pH} 7}$ $195=3.4 \mathrm{M}^{-1} \mathrm{~s}^{-1}$.

\subsection{Product analyses and reaction mechanisms}

\subsubsection{Triethylamine-ozone reaction}

Transformation products. The abatement of triethylamine and the evolution of transformation products

199 as a function of the ozone doses were measured in presence of $t$-butanol as a hydroxyl radical scavenger

200 (Figure 1a). All compounds presented in Figure 1 were quantified by various analytical methods with

201 reference standards (Text S3). Triethylamine (94 $\mu \mathrm{M}$ initial concentration) gradually decreased for ozone

202 doses of $\leq 100 \mu \mathrm{M}$ and was completely abated for an ozone dose of $\sim 110 \mu \mathrm{M}$, yielding a molar

203 ozone:triethylamine reaction stoichiometry of about 1 . The major product was triethylamine $N$-oxide, in

204 agreement with previous findings from reactions of tertiary amines with ozone in laboratory- and full-

205 scale studies (Borowska et al., 2016; Bourgin et al., 2018; Knoop et al., 2018; Lange et al., 2006; Muñoz

206 and von Sonntag, 2000a; von Sonntag and von Gunten, 2012; Zimmermann et al., 2012). A minor

207 product is nitroethane, which was formed in small concentrations but gradually built up with increasing 208 ozone doses. Triethylamine $N$-oxide and nitroethane were final products with yields of $87 \%$ and $9 \%$,

209 respectively, based on the abated triethylamine at the highest applied ozone dose (300 $\mu \mathrm{M})$.

210 Diethylamine and $\mathrm{N}$-ethylethanimine oxide were formed as transient products to a lesser extent (insert

211 of Figure 1a) and were subsequently degraded at high ozone doses, likely concomitant with the

212 formation of nitroethane (see the section 3.2.2). The sum of the concentrations of all nitrogen species is 213 presented as a mass balance in Figure 1a. The mass balance was maintained at $89-110 \%$ for all ozone 
214 doses. As this is a very reasonable mass balance for a product study, it can be concluded that no major

215 transformation products are missing for the ozone-induced transformation of triethylamine.

216 Reactive oxygen species. The reaction of triethylamine with ozone exerted a high yield of ${ }^{1} \mathrm{O}_{2}(70 \%$ of

217 the consumed ozone, Table 2 ). In contrast, the $\bullet \mathrm{OH}$ yield was only $6.4 \%$. These yields are roughly within

218 the same range compared to previously reported values of $80 \%$ for ${ }^{1} \mathrm{O}_{2}$ and $15 \%$ for $\bullet \mathrm{OH}$ (Flyunt et al.,

219 2003; Muñoz et al., 2001). The previously reported ${ }^{1} \mathrm{O}_{2}$ yields were determined without $t$-butanol.

220 Nevertheless, the yields determined under amine-excess conditions (amine:ozone $\geq 10$ ) (Muñoz et al.,

221 2001) can be compared to our results because the effect of $\bullet \mathrm{OH}$ on amine and ozone concentrations is

222 minimal under these conditions despite the absence of an $\bullet \mathrm{OH}$ scavenger. We also measured ${ }^{1} \mathrm{O}_{2}$ yields

223 for conditions with the amine in excess without $t$-butanol and obtained comparable results (70 \%, Table

224 S3). The yields of ${ }^{1} \mathrm{O}_{2}$ and $\bullet \mathrm{OH}$ correspond well to the product formation trend where triethylamine $\mathrm{N}$ -

225 oxide (yielding ${ }^{1} \mathrm{O}_{2}$ ) was observed in much higher concentrations than the dealkylated amine,

226 diethylamine (yielding $\bullet \mathrm{OH}$ ) and its identified transformation products, nitroethane (see the section

227 3.2.2). Both results from the formation of transformation products and the detection of reactive oxygen

228 species indicate that the reaction of triethylamine with ozone predominantly occurs via oxygen transfer

229 forming triethylamine $\mathrm{N}$-oxide and ${ }^{1} \mathrm{O}_{2}$ rather than via electron transfer forming diethylamine and $\bullet \mathrm{OH}$.

230 Reaction pathways. The experimental findings on the triethylamine-ozone reactions are described well

231 by two pathways: The formation of triethylamine $\mathrm{N}$-oxide and ${ }^{1} \mathrm{O}_{2}$ via an oxygen transfer and the

232 formation of diethylamine and $\bullet \mathrm{OH}$ via an electron transfer mechanism (Figure 2 ). The extent of oxygen

233 transfer and electron transfer was further elucidated by calculating the yields of transformation

234 products and reactive oxygen species. The concentrations of the products were divided by the

235 concentrations of abated triethylamine determined at an ozone dose of $93 \mu \mathrm{M}(\Delta[$ Triethylamine $]=83$

$236 \mu \mathrm{M}$ ) and expressed in percentage in Figure 2. For the reactive oxygen species, the yields determined 
with regard to consumed ozone in Table 2 were converted to the yields per abated triethylamine to be

238 comparable with the transformation product yields (e.g., the converted ${ }^{1} \mathrm{O}_{2}$ yield $=\left({ }^{1} \mathrm{O}_{2} / \mathrm{O}_{3}\right) \times\left[\mathrm{O}_{3}\right] /$

$239 \Delta[$ Triethylamine $]=0.70 \times 93 \mu \mathrm{M} / 83 \mu \mathrm{M}=78 \%)$. In summary, of the abated $83 \mu \mathrm{M}$ of triethylamine at

$24093 \mu \mathrm{M}$ of ozone, $88 \pm 3 \%$ was transformed into triethylamine $N$-oxide and $5 \pm 1 \%$ into diethylamine.

241 The yields of reactive oxygen species matched quite well the yields of the transformation product

242 counterparts, namely $78 \pm 3 \%$ of ${ }^{1} \mathrm{O}_{2}$ and $7 \pm 0.3 \%$ of $\bullet \mathrm{OH}$.

\subsubsection{Diethylamine-ozone reaction}

244 Transformation products. Figure $1 \mathrm{~b}$ shows the abatement of diethylamine and the corresponding

245 product formation upon ozonation. In contrast to triethylamine, diethylamine required a much higher

246 specific ozone dose with a molar stoichiometry ozone:diethylamine of about 4 for a complete

247 abatement. Nitroethane, a highly oxidized form of nitrogen with an oxidation state of +3 (in comparison

248 to -3 of diethylamine), was the major product with a $64 \%$ yield based on the diethylamine abatement at

$249300 \mu \mathrm{M}$ ozone. $N$-ethylethanimine oxide and ethylamine were additionally detected as minor products

250 with yields of $2 \%$ and $7 \%$, respectively, at $300 \mu \mathrm{M}$ ozone (insert in Figure $1 \mathrm{~b}$ ). $N$-ethylethanimine oxide

251 is a $\mathrm{N}$-oxide of an imine derivative of diethylamine and belongs to the class of nitrones. $\mathrm{N}$ -

252 ethylethanimine oxide was formed in small quantities for ozone doses $\leq 100 \mu \mathrm{M}$ and was abated again

253 for higher ozone doses. The decline in the $N$-ethylethanimine oxide concentrations is likely associated

254 with the formation of nitroethane. Nitrones have been suggested as intermediates during the

255 transformation of secondary amines into nitroalkanes upon ozonation (Bailey et al., 1978; McCurry et al.,

256 2016). Ethylamine, the other minor product, gradually increased with increasing ozone doses, persisting

257 as a final product along with nitroethane. The nitrogen mass balance was well maintained up to an

258 ozone dose of $100 \mu \mathrm{M}$ but fell short by $10-24 \%$ for higher ozone doses, which is still reasonable

259 compared to typical product studies. Attempts were made to identify $N, N$-diethylhydroxylamine as 
another possible transformation product by LC-MS/MS with the reference standard, but this compound

261 was not detected $(\mathrm{LOQ}=2.5 \mu \mathrm{M})$ at any ozone dose.

262 Reactive oxygen species. During the diethylamine-ozone reaction, $46 \%$ of ${ }^{1} \mathrm{O}_{2}$ and $26 \%$ of $\bullet \mathrm{OH}$ were

263 found relative to the consumed ozone (Table 2). The ${ }^{1} \mathrm{O}_{2}$ yield was higher than the reported value of $20 \%$

264 (Muñoz et al., 2001). However, a ${ }^{1} \mathrm{O}_{2}$ yield of $29 \%$ (Table S3) determined under similar conditions to the

265 previous study (i.e., amine excess and without $t$-butanol) was closer to the reported value. The $\bullet \mathrm{OH}$

266 yield was similar to a reported value of $28 \%$ for piperidine which contains a secondary amine moiety

267 (Tekle-Röttering et al., 2016). The relatively high $\bullet \mathrm{OH}$ yield found in the reaction of diethylamine with

268 ozone does not match to the low formation of the corresponding dealkylated product, ethylamine.

269 There seems another reaction pathway responsible for the excess of $\bullet \mathrm{OH}$ apart from the electron

270 transfer pathway of diethylamine leading to ethylamine (see the section 3.2.3).

271 Reaction pathways. The diethylamine-ozone reaction can also be described by oxygen transfer and

272 electron transfer pathways (Figure 3). However, it entailed secondary ozone reactions with the primary

273 transformation products, which makes the elucidation of the reaction mechanism more complicated

274 than in the case of triethylamine. The yields of the identified transformation products at an ozone dose

275 of $93 \mu \mathrm{M}$ was calculated in analogy to the triethylamine-ozone reaction (transformation product

276 formed/diethylamine abated): $26 \pm 1 \% N$-ethylethanimine oxide, $69 \pm 13 \%$ nitroethane, and $8 \pm 1 \%$

277 ethylamine. The total yield of the products with the oxygen addition ( $N$-ethylethanimine oxide and

278 nitroethane) was about $95 \%$, outweighing the yield of the dealkylated amine (ethylamine, $8 \%$ ). This

279 suggests that the diethylamine-ozone reaction also predominantly undergoes an oxygen transfer

280 pathway (step (a), Figure 3). However, the reactive oxygen species yields were much higher than the

281 yields of the corresponding transformation products: $186 \%$ for ${ }^{1} \mathrm{O}_{2}$ and $105 \%$ for $\bullet \mathrm{OH}$ due to the little

282 abatement of diethylamine $(\Delta[$ Diethylamine $]=23 \mu \mathrm{M})$. These high yields of reactive oxygen species as 
well as the high ozone stoichiometry (4 mole equivalents of ozone, Figure $1 \mathrm{~b}$ ) and the highly oxidized

284 product (nitroethane) imply secondary reactions of primary transformation products with ozone during

285 the diethylamine-ozone reaction. It is hypothesized that $\mathrm{N}, \mathrm{N}$-diethylhydroxylamine might be a transient

286 product. This is in analogy to $\mathrm{N}$-oxides for the case of tertiary amines, as often suggested in other studies

287 on the reaction of secondary amines with ozone (Benner and Ternes, 2009a; Tekle-Röttering et al., 2016;

288 von Gunten, 2003). However, N,N-diethylhydroxylamine was not detected in our experiments. This

289 contrasts a recent finding in the reaction of piperidine (a secondary amine) with ozone where a yield of

$29094 \%$ N-hydroxypiperidine was reported (Tekle-Röttering et al., 2016). The apparent disagreement can

291 be explained by different pH conditions applied in the two studies. In the current study, the experiments

292 were carried out at $\mathrm{pH}$ 7, where the apparent second-order rate constant for the reaction of $N, N$ -

293 diethylhydroxylamine with ozone is more than three orders of magnitude higher than the corresponding

294 rate constant for diethylamine ( $k_{\mathrm{obs}, \mathrm{pH} 7}$, Table 1$)$. Therefore, even if $N, N$-diethylhydroxylamine is formed

295 as a primary transformation product during the diethylamine-ozone reaction, it would quickly react with

296 ozone and be further oxidized, which would hinder its detection. In contrast, the experiment in the

297 previous study was carried out at $\mathrm{pH} 11.5$ where the kinetics for the reactions of ozone with piperidine

298 and $N$-hydroxypiperidine only differ by a factor of two. Under these conditions and in excess of

299 piperidine relative to ozone, $N$-hydroxypiperidine can be detected.

Quantum chemical computations. Quantum chemical computations were performed to calculate

301 aqueous Gibbs free energy of reaction $\left(\Delta G_{a q, r x n}\right)$ for the oxygen transfer and electron transfer pathways

302 of the diethylamine-ozone reaction by assuming $N, N$-diethylhydroxylamine as the primary product of

303 the oxygen transfer pathway (steps (a) and (b) in Figure 3 and Reactions No. 1 and 2 in Table S4). The

304 calculations were made for the initial reaction step of each pathway in which diethylamine and ozone

305 react to form $\mathrm{N}, \mathrm{N}$-diethylhydroxylamine and ${ }^{1} \mathrm{O}_{2}$ via an oxygen transfer (step (a), Figure 3) or

306 diethylaminyl radical $\left(\left(\mathrm{CH}_{3} \mathrm{CH}_{2}\right) \mathrm{N} \bullet\right)$, proton $\left(\mathrm{H}^{+}\right)$, and ozonide radical anion $\left(\mathrm{O}_{3}{ }^{\circ}\right)$ via electron transfer 
(step (b), Figure 3). The $\Delta G_{a q, r x n}$ was compared to estimated values based on more accurate gas-phase reactions for the oxygen transfer pathway (Trogolo et al., 2019) or to reported one-electron standard reduction potentials for the electron transfer pathway (Jonsson et al., 1996; Wardman, 1989). The difference in $\Delta G_{a q, r x n}$ between the purely computed and the estimated values was $<4 \mathrm{kcal} \mathrm{mol}^{-1}$ (details

311 are given in Text S8 and Table S4), and the uncertainty of calculation should be in the same range. The

312 results clearly show that the oxygen transfer pathway $\left(\Delta G_{a q, r x n}=-16.4 \mathrm{kcal} \mathrm{mol}^{-1}\right)$ is thermodynamically

313 more feasible than the electron transfer pathway $\left(\Delta G_{a q, r x n}=+9.3 \mathrm{kcal} \mathrm{mol}^{-1}\right)$. This is another strong 314 indication suggesting a predominance of an oxygen transfer pathway over an electron transfer pathway 315 during the initial phase of the diethylamine-ozone reaction shown in Figure 3.

\subsection{3. $\quad \mathrm{N}, \mathrm{N}$-diethylhydroxylamine-ozone reaction}

317 Transformation products. To further investigate whether $\mathrm{N}, \mathrm{N}$-diethylhydroxylamine can be an

318 intermediate of the diethylamine-ozone reaction, $N, N$-diethylhydroxylamine was treated with ozone 319 separately and its transformation products (Figure 1c) were compared with those of diethylamine 320 (Figure 1b). $\mathrm{N}, \mathrm{N}$-diethylhydroxylamine was indeed transformed to $\mathrm{N}$-ethylethanimine oxide and 321 nitroethane, the identical products as formed in the diethylamine-ozone reaction. $N$-ethylethanimine 322 oxide was detected even for the samples without ozone (i.e., at $0 \mu \mathrm{M}$ ozone), which was due to the 323 spontaneous oxidation of hydroxylamines by oxygen to form nitrones (Johnson et al., 1956). Accordingly, 324 the reaction time was reduced to $3-5$ hours to minimize the autoxidation. $N$-ethylethanimine oxide 325 reached the maximum formation at $150 \mu \mathrm{M}$ ozone where $N, N$-diethylhydroxylamine was completely 326 abated, and decreased for higher ozone doses. The decrease in $\mathrm{N}$-ethylethanimine oxide coincided with 327 a gradual increase in nitroethane formation. Thus, the transformation reaction occurred in the sequence $328 N, N$-diethylhydroxylamine $\rightarrow N$-ethylethanimine oxide $\rightarrow$ nitroethane. The mass balance of $N, N$ - 
diethylhydroxylamine and the detected transformation products was within $82-116 \%$ for the entire range of ozone doses.

331 Reactive oxygen species. Similar yields of ${ }^{1} \mathrm{O}_{2}$ and $\bullet \mathrm{OH}$ were determined for the reaction of $N, N$ -

332 diethylhydroxylamine with ozone ( $38 \%$ and $43 \%$, Table 2 ). The ${ }^{1} \mathrm{O}_{2}$ yield increased to $50 \%$ at

333 amine:ozone molar ratios $>1$ (Table S3). Under these conditions with amine in excess, $\mathrm{N}, \mathrm{N}$ -

334 diethylhydroxylamine was transformed into $N$-ethylethanimine oxide with $100 \%$ yield $(0-150 \mu \mathrm{M}$

335 ozone dose, Figure 1c). Therefore, the initial phase of the $\mathrm{N}, \mathrm{N}$-diethylhydroxylamine-ozone reaction can

336 be characterized by two distinct pathways yielding ${ }^{1} \mathrm{O}_{2}$ and $\bullet \mathrm{OH}$, which both led to the same product, $\mathrm{N}$ -

337 ethylethanimine oxide. To investigate the secondary phase of the $N, N$-diethylhydroxylamine-ozone

338 reaction where $\mathrm{N}$-ethylethanimine oxide was transformed to nitroethane, we attempted to determine

$339{ }^{1} \mathrm{O}_{2}$ yields under ozone excess conditions (amine:ozone $\leq 1$ ) and found the yields decreased as the 340 specific ozone dose increased (Table S3). The low ${ }^{1} \mathrm{O}_{2}$ yields might be underestimated by the excess

341 ozone which could quench ${ }^{1} \mathrm{O}_{2}$ formed during the $\mathrm{N}, \mathrm{N}$-diethylhydroxylamine-ozone reaction. The

342 reaction of ${ }^{1} \mathrm{O}_{2}$ with ozone in the gas phase is known $\left(k=2 \times 10^{6} \mathrm{M}^{-1} \mathrm{~s}^{-1}\right)$ (Wayne and Pitts, 1969).

343 However, currently little information is available for the quenching reaction in the aqueous phase.

344 Comparison of reactive oxygen species yields for diethylamine-and $\mathrm{N}, \mathrm{N}$-diethylhydroxylamine-ozone

345 reactions. The reactive oxygen species yields of $N, N$-diethylhydroxylamine were compared to those of

346 diethylamine to further examine the possibility of forming $N, N$-diethylhydroxylamine as a primary

347 product of the diethylamine-ozone reaction. During the initial phase of the diethylamine-ozone reaction,

$34895 \%{ }^{1} \mathrm{O}_{2}$ and $8 \% \bullet \mathrm{OH}$ would have been formed based on the yields of the corresponding transformation

349 products, $\mathrm{N}, \mathrm{N}$-diethylhydroxylamine and ethylamine (steps (a) and (b), Figure 3). As mentioned above,

350 the total ${ }^{1} \mathrm{O}_{2}$ and $\bullet \mathrm{OH}$ yields determined for the diethylamine-ozone reaction were $186 \%$ and $105 \%$,

351 respectively, thus the remaining $91 \%{ }^{1} \mathrm{O}_{2}$ and $97 \% \bullet \mathrm{OH}$ would have resulted from secondary reactions 
352 of a primary transformation product, e.g., $\mathrm{N}, \mathrm{N}$-diethylhydroxylamine. The hypothetical ${ }^{1} \mathrm{O}_{2}$ and $\bullet \mathrm{OH}$

353 yields for the reaction of $\mathrm{N}, \mathrm{N}$-diethylhydroxylamine with ozone were estimated for the condition where

$354 N$-ethylethanimine oxide and nitroethane were formed with $26 \%$ and $69 \%$ yields, respectively, as found

355 in the diethylamine-ozone reaction. The ozone dose required for these specific product yields was

356 approximately $270 \mu \mathrm{M}$ (shown as a vertical line in Figure $1 \mathrm{c}$ ) for $N, N$-diethylhydroxylamine with an initial

357 concentration of $\sim 110 \mu \mathrm{M}$. For this ozone dose, $N, N$-diethylhydroxylamine was transformed to $31 \mu \mathrm{M} N$ -

358 ethylethanimine oxide ( $29 \%$ of the abated $N, N$-diethylhydroxylamine) and $80 \mu \mathrm{M}$ nitroethane $(72 \%)$

359 based on the simulated concentrations of the products (dotted lines in Figure 1c; details on the

360 simulation are discussed in the section 3.2.4.). Converting the ${ }^{1} \mathrm{O}_{2}$ and $\bullet \mathrm{OH}$ yields determined with

361 regard to ozone ( $38 \%$ and $43 \%$, Table 2 ) into the yields per abated $\mathrm{N}, \mathrm{N}$-diethylhydroxylamine with $\left[\mathrm{O}_{3}\right]$

$362=270 \mu \mathrm{M}$ and $\Delta[\mathrm{N}, \mathrm{N}$-diethylhydroxylamine $]=110 \mu \mathrm{M}$ resulted in $93 \%{ }^{1} \mathrm{O}_{2}$ and $106 \% \bullet \mathrm{OH}$. This agrees

363 well with the aforementioned hypothetical yields, supporting $N, N$-diethylhydroxylamine as an

364 intermediate of the diethylamine-ozone reaction.

365 Detailed reaction mechanisms. N,N-diethylhydroxylamine is a highly probable intermediate of the

366 diethylamine-ozone reaction with a high theoretical yield of $95 \%$. Therefore, it is important to

367 understand how $\mathrm{N}, \mathrm{N}$-diethylhydroxylamine reacts with ozone to obtain a complete picture of the

368 diethylamine-ozone reaction. Clearly, our results show that $N, N$-diethylhydroxylamine was

369 quantitatively transformed into $N$-ethylethanimine oxide upon ozonation during the initial phase of the

370 reaction (Figure 1c). Based on the similarly high yields of ${ }^{1} \mathrm{O}_{2}$ and $\bullet \mathrm{OH}$ from $\mathrm{N}, \mathrm{N}$-diethylhydroxylamine

371 (38\% for ${ }^{1} \mathrm{O}_{2}$ and $43 \%$ for $\bullet \mathrm{OH}$, Table 2), both oxygen transfer and electron transfer seem to play an

372 important role in the initial transformation of $\mathrm{N}, \mathrm{N}$-diethylhydroxylamine into $\mathrm{N}$-ethylethanimine oxide.

373 The oxygen transfer pathway would proceed via a $\mathrm{N}^{+}-\mathrm{O}-\mathrm{O}-\mathrm{O}^{-}$adduct from an ozone attack on $\mathrm{N}, \mathrm{N}$ -

374 diethylhydroxylamine, which would then degrade into $\mathrm{N}$-ethylethanimine oxide, ${ }^{1} \mathrm{O}_{2}$, and water (step (c),

375 Figure 4). The formation of a $\mathrm{N}^{+}-\mathrm{O}-\mathrm{O}-\mathrm{O}^{-}$adduct of a hydroxylamine was suggested by a study on the 
reaction of a primary amine with ozone in an organic solvent where a hydroxylamine was expected as a

377 reaction intermediate, but with lack of experimental evidence (Bailey and Keller, 1968). In contrast, the

378 electron transfer pathway would result in diethylnitroxide and ozonide radical anion $\left(\mathrm{O}_{3}{ }^{-{ }^{-}}\right)$as primary

379 products (step (d), Figure 4). Electron transfer pathways forming nitroxide compounds were often

380 suggested by other studies to describe the oxidation of hydroxylamines, e.g., with ozone as an oxidant in

381 the gas phase (Olszyna and Heicklen, 1976), with molecular oxygen (Johnson et al., 1956), with ${ }^{1} \mathrm{O}_{2}$

382 (Encinas et al., 1987), and during photooxidation (Bilski et al., 1993). The formation of diethylnitroxide

383 during the photooxidation of $N, N$-diethylhydroxylamine was experimentally confirmed by detecting the

384 characteristic EPR signal (Bilski et al., 1993). Nitroxides containing $\alpha$-hydrogens are susceptible to an

385 attack by other radicals to form nitrones (Amar et al., 2015). Similarly, an $\alpha$-hydrogen of diethylnitroxide

386 can be abstracted by other radicals and transformed into $N$-ethylethanimine oxide (step (h), Figure 4).

387 Such radicals can be diethylnitroxide itself inducing a bimolecular reaction forming $N$-ethylethanimine

388 oxide and $N, N$-diethylhydroxylamine (Adamic et al., 1970) or $t$-butanol derived peroxyl radicals (e.g.,

$389 \mathrm{C}\left(\mathrm{CH}_{3}\right)_{2}(\mathrm{OH}) \mathrm{CH}_{2} \mathrm{OO} \bullet$, hereafter referred to $t$-BuOO•) (Flyunt et al., 2003) likely present in the reaction

390 system with high yields of $\bullet \mathrm{OH}$. Alternatively, diethylnitroxide can further react with ozone to form an

391 aminyl radical $\left(\mathrm{R}_{2} \mathrm{~N} \bullet\right)$, which will likely further react with ozone and cause an ozone-consuming chain

392 reaction (steps (e) and (f), Figure 4) (Sein et al., 2008; von Sonntag and von Gunten, 2012) or react also

393 with $t$-BuOO $\bullet$ to decompose to 2-Methyl-1,2-propanediol and $N$-ethylethanimine oxide (step (i), Figure

394 4). The ozone reaction kinetics of diethylnitroxide have not been determined yet. A similar compound

395 with a nitroxide group but with no $\alpha$-hydrogen, TEMPO, has a very high second-order rate constant for

396 its reaction with ozone $\left(k_{03}=10^{7} \mathrm{M}^{-1} \mathrm{~s}^{-1}\right)$ (Muñoz and von Sonntag, 2000b). As the calculated $\Delta \mathrm{G}_{\mathrm{aq}, \mathrm{rxn}}$ for

397 the diethylnitroxide-ozone reaction (-16.7 $\mathrm{kcal} \mathrm{mol}^{-1}$, step (e) in Figure 4) is slightly energetically less

398 favorable than the reported $\Delta \mathrm{G}_{\mathrm{aq}, \mathrm{rxn}}$ for the TEMPO-ozone reaction (-23.2 $\mathrm{kcal} \mathrm{mol}^{-1}$ ) (Naumov and von

399 Sonntag, 2011), the kinetics of the diethylnitroxide-ozone reaction may be lower than $10^{7} \mathrm{M}^{-1} \mathrm{~s}^{-1}$. In 
400

401

402

403

404

405

406

407

408

409

410

411

412

413

414

415

416

417

418

419

420

421

422

contrast, the kinetics of the reaction of diethylnitroxide with radical species vary widely from $8.0 \times 10^{2}$ $\mathrm{M}^{-1} \mathrm{~s}^{-1}$ (as the bimolecular reaction of diethylnitroxide) (Ingold et al., 1971) to $2.8 \times 10^{7} \mathrm{M}^{-1} \mathrm{~s}^{-1}$ (as the reaction of TEMPO with $t$-BuOO•) (Goldstein and Samuni, 2007). Based on the available kinetic information, both reactions of diethylnitroxide with ozone and with radical seem probable, but we still propose that the radical reaction outcompetes the ozone reaction because of the following reasons: (1) Diethylaminyl radical resulted from the further ozone reaction would degrade into ethylamine via 1,2-H shift followed by a reaction with $\mathrm{O}_{2}$ and hydrolysis (step (g), Figure 4) (von Sonntag and von Gunten, 2012), which conflicts with the quantitative formation of $N$-ethylethanimine oxide as a primary product of the $\mathrm{N}, \mathrm{N}$-diethylhydroxylamine-ozone reaction (Figure 1c); (2) A catalytic ozone consumption accompanied with the further ozone reactions (steps (e) and (f)) is inconsistent with the relatively low stoichiometry of about 1.5 mole equivalents of ozone for the initial phase of the $N, N$ diethylhydroxylamine-ozone reaction (Figure 1c).

Quantum chemical computations. Quantum chemical computations of the $\Delta \mathrm{G}_{\mathrm{aq}, \mathrm{rxn}}$ for the $N, N$ diethylhydroxylamine-ozone reaction were performed to test for an oxygen transfer or an electron transfer as the initial reaction step (steps (c) and (d) in Figure 4 and Reactions No. 3 and 4 in Table S4). The results showed that the oxygen transfer pathway is significantly and thermodynamically more favorable than the electron transfer pathway $\left(-61.2 \mathrm{kcal} \mathrm{mol}^{-1}\right.$ for the oxygen transfer, $-6.1 \mathrm{kcal} \mathrm{mol}^{-1}$ for the electron transfer). However, it is worth to note that the electron transfer pathway is exergonic for the $N, N$-diethylhydroxylamine-ozone reaction, in contrast to the diethylamine-ozone reaction where the $\Delta G_{a q, r x n}$ of the electron transfer pathway is $+9.3 \mathrm{kcal} \mathrm{mol}^{-1}$. This implies that $N, N$-diethylhydroxylamineozone reaction may have a higher probability to undergo an electron transfer pathway than the diethylamine-ozone reaction, which is confirmed by similar ${ }^{1} \mathrm{O}_{2}$ and $\bullet \mathrm{OH}$ yields.

\subsection{4. $\quad N$-ethylethanimine oxide-ozone reaction}


424 reaction is the transformation of $\mathrm{N}$-ethylethanimine oxide to nitroethane. An ozonation experiment was 425 carried out for $\mathrm{N}$-ethylethanimine oxide using the synthesized stock described in Text S1 to investigate if 426 it could be a transient product with a high yield of nitroethane. Nitroethane was indeed identified as a 427 major product with a $73 \%$ yield based on the abated $N$-ethylethanimine oxide at $300 \mu \mathrm{M}$ ozone (Figure 428 S13). However, there were a few distinguishing features observed in this separate ozonation experiment 429 with $\mathrm{N}$-ethylethanimine oxide as a starting material, compared to the $\mathrm{N}, \mathrm{N}$-diethylhydroxylamine-ozone 430 reaction (Figure 1c) where $N$-ethylethanimine oxide was formed as an intermediate and further 431 degraded. We assume the difference was caused by a spontaneous dimerization of $N$-ethylethanimine 432 oxide (Ali et al., 2010; Roca-López et al., 2014), which contaminated the primary stock solution used in 433 the separate ozonation experiment and affected the reaction of $N$-ethylethanimine oxide with ozone 434 (Text S7). Therefore, for further discussions regarding $N$-ethylethanimine oxide, we rely on the result 435 from the $N, N$-diethylhydroxylamine-ozone reaction at high ozone doses $(100-300 \mu \mathrm{M})$. Under these 436 conditions, $\mathrm{N}$-ethylethanimine oxide is formed in situ and not affected by dimerization. Because of these 437 experimental shortcomings, also the results of the reactive oxygen species in the experiments with $N$ 438 ethylethanimine oxide should be interpreted cautiously by taking the presence of a dimer into account. Kinetic simulation: $\mathrm{N}, \mathrm{N}$-diethylhydroxylamine- and $\mathrm{N}$-ethylethanimine oxide-ozone reactions. Based on the information obtained so far, we performed kinetic simulations to describe the evolution of $N, N$ -

441 diethylhydroxylamine, $N$-ethylethanimine oxide, and nitroethane during the $N, N$-diethylhydroxylamine442 ozone reaction by using the Kintecus software (www.kintecus.com) (Ianni, 2017) (Table S5 and Figure 1c, 443 dotted lines). The kinetic model contained the initial transformation reaction of $N, N$ -

444 diethylhydroxylamine to $\mathrm{N}$-ethylethanimine oxide, diethylnitroxide, and an unknown radical species, $\mathrm{X}$, 445 via oxygen transfer and electron transfer pathways with a 1:1 branching ratio. $\mathrm{X}$ is a radical species (e.g., $446 t$-BuOO•) derived from the scavenging reaction of $\bullet \mathrm{OH}$ with $t$-butanol, formed by the electron transfer 
447 448

reaction along with diethylnitroxide. The 1:1 ratio was selected based on the similar yields of ${ }^{1} \mathrm{O}_{2}$ and $\bullet \mathrm{OH}$, the indicators of oxygen transfer and electron transfer, for the conditions where $\mathrm{N}, \mathrm{N}$ diethylhydroxylamine was in molar excess of ozone (i.e., amine:ozone $>1$, Table S3 and Figure S12). The ensuing products of electron transfer, diethylnitroxide and X, react with each other and subsequently form $N$-ethylethanimine oxide. Additionally, the autoxidation of $N, N$-diethylhydroxylamine was included assuming oxygen saturation at $20^{\circ} \mathrm{C}\left(\left[\mathrm{O}_{2}(\mathrm{aq})\right] \sim 9 \mathrm{mg} / \mathrm{L}\right)$. A bimolecular reaction of diethylnitroxide to form $N, N$-diethylhydroxylamine and $N$-ethylethanimine oxide was also included to describe the decay of diethylnitroxide under conditions without ozone ( $0 \mu \mathrm{M}$ ozone). Lastly, two more reaction steps were added to describe the transformation of $\mathrm{N}$-ethylethanimine oxide into nitroethane via an unknown intermediate, $\mathrm{Y}$, which was assumed to react very fast with ozone (assumed $k_{\mathrm{obs}, \mathrm{pH7}}=1 \times 10^{6} \mathrm{M}^{-1} \mathrm{~s}^{-1}$ ) to form nitroethane. The simulation results shown in Figure 1c (dotted lines) are in reasonable agreements with the experimental findings of the $N, N$-diethylhydroxylamine-ozone reaction which formed $N$ ethylethanimine oxide and nitroethane in a sequential order.

Detailed reaction mechanisms. Compounds containing $\mathrm{C}-\mathrm{N}$ double bonds like nitrones and oximes typically form C-nitroso compounds upon ozonation according to the studies conducted in organic solvents (Bailey et al., 1978; Erickson et al., 1969; Riebel et al., 1960). Similarly, $N$-ethylethanimine oxide could react with ozone to form nitrosoethane which would be further oxidized by ozone to form nitroethane (steps $(\mathrm{j})-(\mathrm{k})$, Figure S17). However, as the nitroso moiety is a strong electron-withdrawing group, nitrosoethane cannot be the intermediate $\mathrm{Y}$ hypothesized to be highly reactive to ozone in the kinetic simulation. This was tested by a kinetic simulation substituting nitrosoethane for $Y$ and using the same kinetic model but with a different $k_{\mathrm{obs}, \mathrm{pH} 7}$ of the reaction No. 6 set at $1.0 \times 10^{2} \mathrm{M}^{-1} \mathrm{~s}^{-1}$ instead of 1.0 $\times 10^{6} \mathrm{M}^{-1} \mathrm{~s}^{-1}$ (Table S6). The new model with nitrosoethane as an intermediate did not perform as well as the previous one, featuring a lower ozone stoichiometry of the abatement of $N$-ethylethanimine oxide than the measured value (Figure S16b). Another possible mechanism of the $N$-ethylethanimine oxide- 
471 ozone reaction can be a Criegee-type mechanism forming an ozonide via a cycloaddition of ozone to the

472 C-N double bond (step (I), Figure S17) (Criegee, 1975; Dowideit and von Sonntag, 1998). The ozonide

473 would dissociate into nitroethane and a peroxide intermediate. The latter would subsequently react

474 with water to form acetaldehyde and hydrogen peroxide (Criegee and Wenner, 1949; Criegee, 1975). To

475 test this hypothesis, the formation of hydrogen peroxide was determined in ozonated $\mathrm{N}$ -

476 ethylethanimine oxide samples. The $N$-ethylethanimine oxide solution was prepared in situ by oxidizing

$477 \sim 100 \mu \mathrm{M} N, N$-diethylhydroxylamine with $180 \mu \mathrm{M}$ ozone to ensure all $N, N$-diethylhydroxylamine was

478 converted to $N$-ethylethanimine oxide. Thereafter, $100 \mu \mathrm{M}$ ozone was added to the $N$-ethylethanimine

479 oxide solution. The concentrations of hydrogen peroxide in the $\mathrm{N}$-ethylethanimine oxide solution before

480 and after the ozone addition remained the same (16 $\pm 4 \mu \mathrm{M}$ for both). This confirms that hydrogen

481 peroxide was not formed during the reaction of $\mathrm{N}$-ethylethanimine oxide with ozone and thus, makes

482 the Criegee-type mechanism very unlikely. The other hypothesis is an electron transfer pathway forming

483 a $N$-ethylethanimine oxide radical cation and an ozonide radical anion (step (m), Figure S17). This

484 pathway can explain the possibly high $\bullet \mathrm{OH}$ yield of $\mathrm{N}$-ethylethanimine oxide $(43 \%$, Table 2$)$. One-

485 electron oxidation of nitrones has been postulated as an alternative spin trapping mechanism when

486 nitrones were used as radical spin traps (Eberson, 1994; Zubarev and Brede, 1994). The resulting nitrone

487 radical cations were detected experimentally (Zubarev and Brede, 1994). However, little is known

488 whether a similar pathway can be applied to the ozone reaction and how the radical cation further

489 degrades into nitroethane.

490 Quantum chemical computations. The hypothesized mechanisms of the $N$-ethylethanimine oxide-ozone 491 reaction (steps (j) and (I), Figure S17) were examined by calculating $\Delta \mathrm{G}_{\mathrm{aq}, \mathrm{rxn}}$ of the reactions. The $\Delta \mathrm{G}_{\mathrm{aq}, \mathrm{rxn}}$ 492 of the reaction step $(\mathrm{m})$ could not be calculated because of an unreliable result of the computation of 493 the $\mathrm{N}$-ethylethanimine oxide radical cation at the $\operatorname{CCSD}(\mathrm{T}) /$ jul-cc-pVTZ level, resulting in T1 diagnostic > 4940.03 (Lee and Taylor, 1989). Besides the ozone reactions, the hydrolysis of $N$-ethylethanimine oxide 
forming $N$-ethylhydroxylamine and acetaldehyde (step (n), Figure S17), suggested by an earlier study

496 (von Gunten, 2003), was also examined because this could compete with the further reaction of $\mathrm{N}$ -

497 ethylethanimine oxide with ozone. The calculations show that the further reactions with ozone are

498 thermodynamically more feasible than the hydrolysis which is endergonic $\left(-40.8 \mathrm{kcal} \mathrm{mol}^{-1}\right.$ and $-70.8 \mathrm{kcal}$

$499 \mathrm{~mol}^{-1}$ for the ozone reactions and $+8.4 \mathrm{kcal} \mathrm{mol}^{-1}$ for hydrolysis, steps (j), (I), and (n) in Figure S17 and

500 Reaction No. 6-8 in Table S4). However, despite the thermodynamic feasibility of the reaction steps (j)

501 and (I), neither of them were justified by the experimental findings as discussed above. This

502 demonstrates that the results from quantum chemical computations must be interpreted cautiously and

503 considered as supplementary information to experimental findings.

504 Kinetic simulation: diethylamine-ozone reaction. Finally, a kinetic simulation for the diethylamine-ozone 505 reaction was carried out (Table S7 and Figure $1 \mathrm{~b}$, dotted lines). The kinetic model included the initial

506 transformation reaction of diethylamine to $\mathrm{N}, \mathrm{N}$-diethylhydroxylamine and diethylaminyl radical with a

507 9:1 branching ratio based on the product yields. The follow-up reaction steps were applied as in the 508 model for the $\mathrm{N}, \mathrm{N}$-diethylhydroxylamine-ozone reaction (Table S5). The trends for the abatement of 509 diethylamine and the evolution of the various transformation products were well described. However, 510 the simulated concentrations of the final products (nitroethane and ethylamine) at $300 \mu \mathrm{M}$ ozone dose 511 were about $50 \%$ higher than the measured concentrations (Figure 1b). For such a complex reaction 512 system, this is a reasonable outcome.

\subsubsection{Ethylamine-ozone reaction}

514 Transformation products. About 5.5 molar equivalents of ozone were required for a complete

515 abatement of ethylamine (Figure 1d). Nitroethane was the major product with close to $100 \%$ yields at

516 all ozone doses, resulting in a very good mass balance. Therefore, only very limited additional products

517 are expected from the ethylamine-ozone reaction. The high yield of nitroethane observed in the 
ethylamine-ozone reaction is in agreement with a recent study that found $100 \%$ nitromethane from

519 methylamine with a molar ozone:methylamine ratio of 12 (McCurry et al., 2016). However, these results

520 disagree with previous studies, where nitrate was detected as a final product from the ozone reactions

521 of ammonia (Hoigné and Bader, 1978) and amino acids containing a primary amine moiety (Berger et al.,

522 1999; de Vera et al., 2017; Le Lacheur and Glaze, 1996). In the current study, only traces of nitrite and

523 nitrate were detected from ethylamine over the entire range of ozone doses $(<1 \%$, not shown in Figure

524 1d). Additional ozonation experiments were carried out with ozone:ethylamine ratios of 20, but still only

525 about $10 \%$ nitrate was detected. This is far smaller than previously reported nitrate yields from amino

526 acids (glycine and serine) of 85 - $90 \%$ with molar ozone:model compound ratios of 5-20 (Berger et al.,

527 1999; de Vera et al., 2017; Le Lacheur and Glaze, 1996). The discrepancy may be due to the presence of

528 a carboxylic group in the amino acids, which alters the reaction pathway to favor nitrate rather than

529 nitroalkanes as final products (see the section "primary amines vs amino acids" below). Ammonia, a

530 dealkylated product from ethylamine, is unlikely to be formed, because the nitrogen mass balance was

531 completed by nitroethane alone. No ammonia formation was also reported in the oxidation of glycine by

532 ozone in presence of a radical scavenger (Berger et al., 1999).

533 Reactive oxygen species. Similar yields of ${ }^{1} \mathrm{O}_{2}$ and $\bullet \mathrm{OH}$ were determined for the ethylamine-ozone

534 reaction ( $27 \%$ and $33 \%$ relative to the consumed ozone for ${ }^{1} \mathrm{O}_{2}$ and $\bullet \mathrm{OH}$, respectively, Table 2 ). The ${ }^{1} \mathrm{O}_{2}$

535 yield was slightly higher than the previously reported value of $17 \%$ (Muñoz et al., 2001). The $\bullet O H$ yield

536 was similar to the yield from glycine which contains a primary amine moiety (de Vera et al., 2017).

537 Similar to the diethylamine-ozone reaction, the significant yield of $\bullet \mathrm{OH}$ seems to be a result of

538 secondary ozone reactions of primary transformation products rather than from the initial phase of the

539 ethylamine-ozone reaction. 
Reaction pathways. The ethylamine-ozone reaction can be understood similarly to the diethylamine-

541 ozone reaction as it was characterized by the same features: high ozone stoichiometry, the formation of 542 a highly oxidized product (nitroethane), and high yields of reactive oxygen species per abated amine 543 (Figure 5). The yields of nitroethane and reactive oxygen species $\left({ }^{1} \mathrm{O}_{2}\right.$ and $\left.\bullet \mathrm{OH}\right)$ at $93 \mu \mathrm{M}$ ozone are $544100 \%, 120 \%$ and $146 \%$, respectively, where $\Delta$ [Ethylamine] = $21 \mu \mathrm{M}$. The ethylamine-ozone reaction 545 mainly underwent oxygen transfer reaction based on a $100 \%$ yield of nitroethane. Accordingly, $N$ 546 ethylhydroxylamine and ${ }^{1} \mathrm{O}_{2}$, the primary transformation product and the reactive oxygen species of the 547 oxygen transfer pathway, would be formed with $100 \%$ theoretical yields. The remaining ${ }^{1} \mathrm{O}_{2}$ and $\bullet \mathrm{OH}$ 548 yields ( $20 \%$ and $146 \%$ ) should be associated with secondary reactions leading to nitroethane. However, 549 considering the high ozone stoichiometry of 5.5 mole equivalents of ozone (or $550 \%$ ozone in relation 550 to abated ethylamine), the total reactive oxygen species yield ( $266 \%$ ) was too low. Thus, more reactive 551 oxygen species (e.g., ${ }^{1} \mathrm{O}_{2}$ and $\bullet \mathrm{OH}$ which might have been underestimated or superoxide radical and 552 hydrogen peroxide which have not been determined) seems to be involved in the secondary reactions 553 than what were actually measured.

554 Detailed reaction mechanisms. $\mathrm{N}$-ethylhydroxylamine is expected as a primary transformation product 555 via oxygen transfer in analogy to $N, N$-diethylhydroxylamine of the diethylamine-ozone reaction. Similar 556 to $N, N$-diethylhydroxylamine, $N$-ethylhydroxylamine $\left(k_{\mathrm{obs}, \mathrm{pH}} 7 \sim 10^{5} \mathrm{M}^{-1} \mathrm{~s}^{-1}\right.$, Table 1$)$ reacts much faster 557 with ozone than the parent amine, wherefore, it was not detectable and the formation of further 558 oxidized products can be expected. During the further reaction of $N$-ethylhydroxylamine with ozone, a 559 dihydroxylamine intermediate would be formed (Figure S18a), as suggested by studies on ozone 560 reactions of primary amines in organic solvents (Bachman and Strawn, 1968; Bailey and Keller, 1968).

561 The dihydroxylamine intermediate would degrade to nitrosoethane or acetaldoxime by releasing water.

562 Neither of these products were identified due to the lack of reference standards or an applicable 563 analytical method. Nitroso compounds and oximes are tautomers of each other and oximes are known 
564 to be the more stable forms (Long et al., 2001). Although the tautomeric equilibrium would favor the

565 formation of acetaldoxime, nitrosoethane still seems a more probable product based on the

566 predominant formation of nitroethane. If acetaldoxime was formed, the major product would have

567 been nitrate, since acetaldoxime is hydrolyzed to hydroxylamine which can react fast with ozone $\left(k_{03}=\right.$

$5682.1 \times 10^{4} \mathrm{M}^{-1} \mathrm{~s}^{-1}$ for hydroxylamine) (Hoigné et al., 1985) to nitrate. Therefore, the high yield of

569 nitroethane supports nitrosoethane as a precursor rather than acetaldoxime.

570 Primary amines vs amino acids. The different nitrate yields for primary amines and amino acids upon

571 ozonation may be related to the secondary reaction pathways involving dihydroxylamines, nitroso

572 compounds, or oximes as intermediates. Ethylamine and glycine, differing only by a substituent of the $\alpha-$

573 carbon (methyl for ethylamine and carboxyl for glycine), are compared in detail in Figure S18. The

574 nitrate yields per abated amines under ozone-excess conditions ( $\geq 5$ molar equivalent ozone) were $10 \%$

575 for ethylamine (determined in this study) and $90 \%$ for glycine (Berger et al., 1999). To explain the high

576 nitrate yield from glycine, we hypothesized that the nitroso intermediate of glycine can not only degrade

577 into nitroacetic acid (McCurry et al., 2016), but also produce nitrate as a final product similar to the

578 oxime counterpart (Figure S18b). This is because the carboxyl group in the nitroso intermediate of

579 glycine can decarboxylate, leaving formaldehyde oxime as the other product. The resulting

580 formaldehyde oxime would be transformed into hydroxylamine and then nitrate in the same manner as

581 the other oxime intermediates. The same decarboxylation mechanism was suggested for oxidation of

582 amino acids by dimethyldioxirane, an electrophilic compound, for which the corresponding oximes and

583 the carboxylic acids (resulted from further decomposition of the oximes) were found as major products

584 (Paradkar et al., 1995). In comparison, the reactions of primary amines with dimethyldioxirane produce

585 nitro compounds with high yields (Murray et al., 1986). Alternatively, it can be hypothesized that the

586 carboxyl group can withdraw electron density from the neighboring $\alpha$-carbon and render the $\alpha$-carbon

587 more acidic and thus prone to lose a proton. As a result, the oxime intermediate may be formed more 
efficiently than the nitroso counterpart. The deprotonation of the $\alpha$-carbon of amino acids has been

589 accepted as a key step of the racemization of amino acids (Smith and Sivakua, 1983). The $\mathrm{p} K_{\mathrm{a}}$ of the $\alpha-$

590 carbon of glycine in the zwitterion form was determined to be 29 in aqueous solution (Rios et al., 2000).

591 With the two additional hydroxyl groups, the $\alpha$-carbon of the dihydroxylamine intermediate of glycine

592 may be characterized by a much lower $\mathrm{p} K_{\mathrm{a}}$. Overall, the involvement of the oxime intermediates, either

593 derived from dihydroxylamine intermediate or from nitroso intermediate, seems a decisive factor to

594 explain the high nitrate yield from amino acids in comparison to primary amines.

\subsubsection{Reaction mechanisms of aliphatic amines with ozone}

Based on the findings of this study as well as available information in literature (Bailey et al., 1978;

Bailey and Keller, 1968; Benner and Ternes, 2009b; Berger et al., 1999; Borowska et al., 2016; de Vera et

al., 2017; Muñoz and von Sonntag, 2000a; Tekle-Röttering et al., 2016, p.; Zimmermann et al., 2012), the

reactions of aliphatic primary, secondary, and tertiary amines with ozone are summarized in Figure 6.

Our study revealed that all amines were predominantly transformed into products containing nitrogen-

601 oxygen bonds, i.e., triethylamine $N$-oxide or nitroethane $(64-100 \%$ of the transformed parent amines

602 at the highest applied ozone dose). Dealkylated products were formed only as small fractions of the

603 transformed parent compounds (0-9\%).

\subsection{Practical implications}

605 Nitroethane was detected as a final product in all tested amine-ozone reactions. The yield was

606 considerable for almost all amines (> $60 \%$ for diethylamine, ethylamine, $N, N$-diethylhydroxylamine, and

$607 \mathrm{~N}$-ethylethanimine oxide) except for triethylamine (9\%). Short-chain aliphatic amines such as

608 methylamine, dimethylamine, ethylamine, and diethylamine are typically present up to $0.1 \mu \mathrm{M}$ in

609 surface waters and up to 5 MM in wastewater effluents (Ábalos et al., 1999; Chen et al., 2014; Hwang et

610 al., 1995; Mitch and Sedlak, 2004; Sacher et al., 1997). Considering the amount of aliphatic amines 
611 formed as breakdown products from more complex organic compounds, the total concentration of the

612 short-chain nitroalkanes derived from aliphatic amines can be higher than $5 \mu \mathrm{M}$ after ozonation. The

613 reactivity of nitroalkanes towards ozone is expected to be low based on the low second-order ozone

614 rate constant of nitroethane determined in this study $\left(k=3.4 \mathrm{M}^{-1} \mathrm{~s}^{-1}\right.$, Table 1$)$. Thus, once formed,

615 nitroalkanes would not be further transformed by ozone but persistent in water as they are not easily

616 hydrolyzed nor biodegradable (USEPA, 1985). Moreover, the volatility of short-chain nitroalkanes is in

617 the same range as trihalomethanes, known disinfection byproducts in chlorinated waters, based on the

618 comparable Henry's constants $\left(2.9 \times 10^{-5}-1.2 \times 10^{-4}\right.$ atm $\mathrm{m}^{3} \mathrm{~mol}^{-1}$ for nitroalkanes and $4.4 \times 10^{-4}-7.8 \times$

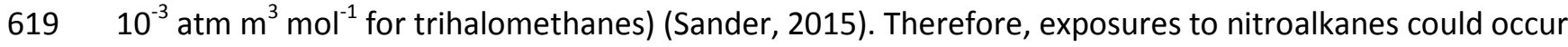

620 via inhalation or dermal adsorption during showering and bathing, similarly to trihalomethanes (WHO,

621 2005). The short-chain nitroalkanes such as nitromethane, nitroethane, 1-nitropropane, and 2-

622 nitropropane are widely used as industrial solvents, building blocks for chemical syntheses, and fuels in

623 combustion engines (Markofsky, 2011). Accordingly, studies on the toxicity of the nitroalkanes have

624 mostly been conducted in the context of occupational exposures at workplaces where the nitroalkanes

625 are used in high concentrations. Exposure to high levels of nitroalkanes causes acute and short-term

626 toxicity (nitrite-induced methemoglobinemia) typically with little lingering effects. Such high levels of

627 nitroalkanes are unlikely to be formed during water and wastewater treatment. Some nitroalkanes

628 (nitromethane and 2-nitropropane) are reasonably anticipated to be human carcinogens (National

629 Toxicology Program, 2016) and effects of long-term exposure to them have been of great concern.

630 Therefore, further information is needed on the occurrence of nitroalkanes during ozonation, especially

631 in the context of wastewater-impacted source waters and water reuse systems, where relatively high

632 concentrations of aliphatic amines are expected in the dissolved organic matter. 


\section{Conclusion}

635

636

637

638

639

640

641

642

643

644

645

646

647

648

649

650

651

652

653

654

655

656

- All amines predominantly underwent oxygen transfer reactions as initial ozone reaction pathways to form major products containing nitrogen-oxygen bonds, e.g., triethylamine $N$-oxide (triethylamine) or nitroethane (diethylamine and ethylamine). The yields of the major products were $69-100 \%$ per abated amines with one molar equivalent of ozone $(93 \mu \mathrm{M}) . N$-dealkylated products were additionally identified for triethylamine and diethylamine, but the yields were lower than $10 \%$. Good nitrogen mass balances were achieved for all amine-ozone reactions (> $70 \%)$.

- $\quad \mathrm{N}, \mathrm{N}$-diethylhydroxylamine, a potential intermediate of the diethylamine-ozone reaction, escaped from our detection because of its high reactivity towards ozone in comparison to the ozone reactivity of diethylamine. However, the measurements of reactive oxygen species $\left({ }^{1} \mathrm{O}_{2}\right.$ and $\bullet \mathrm{OH}$ ), quantum chemical computations, and kinetic simulations support the possibility of forming $N, N$-diethylhydroxylamine during the diethylamine-ozone reaction.

- Different from the triethylamine-ozone reaction, the reactions of diethylamine and ethylamine with ozone were characterized by the high ozone molar stoichiometry (ozone:amine $\geq 4$ ), which resulted in the formation of the highly oxidized product (nitroethane) and the excess formation of ${ }^{1} \mathrm{O}_{2}$ and $\bullet \mathrm{OH}$.

- The high yields of nitroethane from diethylamine- and ethylamine-ozone reactions determined in this study imply significant formation of nitroalkanes during ozonation especially for waters containing high levels of dissolved organic nitrogen (e.g., wastewater-impacted sources waters). Further efforts are required to understand the occurrence of nitroalkanes and their impact on the receiving aquatic environment and human health. 


\section{Acknowledgment}

658 We thank Elisabeth Salhi for her support in the laboratory, Paul Erickson and Kris McNeill for their advice

659 on the singlet oxygen measurement, Marc Bourgin, Philipp Longree and Jakov Bolotin for their support

660 with MS measurements, Peter Tentscher for his help on quantum chemical computations, and Samuel

661 Derrer for the synthesis of $\mathrm{N}$-ethylethanimine oxide.

662

663 


\section{References}

665

666

667

668

669

670

671

672

673

674

675

676

677

678

679

680

681

682

683

684

685

686

687

688

689

690

691

692

693

694

695

696

697

698

699

700

701

702

703

704

705

706

707

708

709
Ábalos, M., Bayona, J.M., Ventura, F., 1999. Development of a Solid-Phase Microextraction GC-NPD Procedure for the Determination of Free Volatile Amines in Wastewater and Sewage-Polluted Waters. Analytical Chemistry 71, 3531-3537. https://doi.org/10.1021/ac990197h

Adamic, K., Bowman, D.F., Ingold, K.U., 1970. Self-reaction of diethylnitroxide radicals. Journal of the American Chemical Society 92, 1093-1094. https://doi.org/10.1021/ja00707a076

Ali, S.A., AlSbaiee, A., Wazeer, M.I.M., 2010. Conformational analysis and inversion process in some perhydrodipyrido[1,2-b;1'2'-e]-1,4,2,5- dioxadiazines. Journal of Physical Organic Chemistry 23, 488-496. https://doi.org/10.1002/poc.1627

Amar, M., Bar, S., Iron, M.A., Toledo, H., Tumanskii, B., Shimon, L.J.W., Botoshansky, M., Fridman, N., Szpilman, A.M., 2015. Design concept for $\alpha$-hydrogen-substituted nitroxides. Nature Communications 6, 6070. https://doi.org/10.1038/ncomms7070

Andrzejewski, P., Kasprzyk-Hordern, B., Nawrocki, J., 2008. N-nitrosodimethylamine (NDMA) formation during ozonation of dimethylamine-containing waters. Water Research 42, 863-870. https://doi.org/10.1016/j.watres.2007.08.032

Bachman, G.B., Strawn, K.G., 1968. Ozone oxidation of primary amines to nitroalkanes. The Journal of Organic Chemistry 33, 313-315. https://doi.org/10.1021/jo01265a062

Bader, H., Hoigné, J., 1981. Determination of ozone in water by the indigo method. Water Research 15, 449-456.

Bailey, P.S., Keller, J.E., 1968. Ozonation of amines. III. tert-Butylamine. The Journal of Organic Chemistry 33, 2680-2684.

Bailey, P.S., Southwick, L.M., Carter Jr, T.P., 1978. Ozonation of nucleophiles. 8. Secondary amines. The Journal of Organic Chemistry 43, 2657-2662.

Becke, A.D., 1993. Density-functional thermochemistry. III. The role of exact exchange. The Journal of Chemical Physics 98, 5648-5652. https://doi.org/10.1063/1.464913

Benner, J., Ternes, T.A., 2009a. Ozonation of Propranolol: Formation of Oxidation Products. Environmental Science \& Technology 43, 5086-5093. https://doi.org/10.1021/es900282c

Benner, J., Ternes, T.A., 2009b. Ozonation of Metoprolol: Elucidation of Oxidation Pathways and Major Oxidation Products. Environmental Science \& Technology 43, 5472-5480. https://doi.org/10.1021/es900280e

Berger, P., Karpel Vel Leitner, N., Doré, M., Legube, B., 1999. Ozone and hydroxyl radicals induced oxidation of glycine. Water Research 33, 433-441. https://doi.org/10.1016/S00431354(98)00230-9

Bilski, P., Motten, A.G., Bilska, M., Chignell, C.F., 1993. The Photooxidation of Diethylhydroxylamine by Rose Bengal in Micellar and Nonmicellar Aqueous Solutions. Photochemistry and Photobiology 58, 11-18. https://doi.org/10.1111/j.1751-1097.1993.tb04896.x

Bond, T., Huang, J., Templeton, M.R., Graham, N., 2011. Occurrence and control of nitrogenous disinfection by-products in drinking water - A review. Water Research 45, 4341-4354. https://doi.org/10.1016/j.watres.2011.05.034

Bond, T., Templeton, M.R., Graham, N., 2012. Precursors of nitrogenous disinfection by-products in drinking water-A critical review and analysis. Journal of Hazardous Materials 235-236, 1-16. https://doi.org/10.1016/j.jhazmat.2012.07.017

Borowska, E., Bourgin, M., Hollender, J., Kienle, C., McArdell, C.S., von Gunten, U., 2016. Oxidation of cetirizine, fexofenadine and hydrochlorothiazide during ozonation: Kinetics and formation of transformation products. Water Research 94, 350-362.

https://doi.org/10.1016/j.watres.2016.02.020 
Bourgin, M., Beck, B., Boehler, M., Borowska, E., Fleiner, J., Salhi, E., Teichler, R., von Gunten, U., Siegrist, H., McArdell, C.S., 2018. Evaluation of a full-scale wastewater treatment plant upgraded with ozonation and biological post-treatments: Abatement of micropollutants, formation of transformation products and oxidation by-products. Water Research 129, 486-498. https://doi.org/10.1016/j.watres.2017.10.036

Chen, G., Liu, J., Liu, M., Li, G., Sun, Z., Zhang, S., Song, C., Wang, H., Suo, Y., You, J., 2014. Sensitive, accurate and rapid detection of trace aliphatic amines in environmental samples with ultrasonicassisted derivatization microextraction using a new fluorescent reagent for high performance liquid chromatography. Journal of Chromatography A 1352, 8-19. https://doi.org/10.1016/j.chroma.2014.05.061

Criegee, R., Wenner, G., 1949. Die Ozonisierung des 9,10-Oktalins. Justus Liebigs Annalen der Chemie 564, 9-15. https://doi.org/10.1002/jlac.19495640103

Criegee, R., 1975. Mechanism of ozonolysis. Angewandte Chemie International Edition 14, 745-752.

de Vera, G.A., Gernjak, W., Weinberg, H., Farré, M.J., Keller, J., von Gunten, U., 2017. Kinetics and mechanisms of nitrate and ammonium formation during ozonation of dissolved organic nitrogen. Water Research 108, 451-461. https://doi.org/10.1016/j.watres.2016.10.021

Dodd, M.C., Kohler, H.-P.E., von Gunten, U., 2009. Oxidation of Antibacterial Compounds by Ozone and Hydroxyl Radical: Elimination of Biological Activity during Aqueous Ozonation Processes. Environmental Science \& Technology 43, 2498-2504. https://doi.org/10.1021/es8025424

Dowideit, P., von Sonntag, C., 1998. Reaction of ozone with ethene and its methyl-and chlorinesubstituted derivatives in aqueous solution. Environmental Science \& Technology 32, 1112-1119.

Eberson, L., 1994. Inverted Spin Trapping. Part 111." Further Studies on the Chemical and Photochemical Oxidation of Spin Traps in the Presence of Nucleophiles. Journal of the Chemical Society, Perkin Transactions 2 0, 171-176.

Eggen, R.I.L., Hollender, J., Joss, A., Schärer, M., Stamm, C., 2014. Reducing the Discharge of Micropollutants in the Aquatic Environment: The Benefits of Upgrading Wastewater Treatment Plants. Environmental Science \& Technology 48, 7683-7689. https://doi.org/10.1021/es500907n

Encinas, M.V., Lemp, E., Lissi, E.A., 1987. Interaction of singlet oxygen [O2(1 $\Delta)]$ with aliphatic amines and hydroxylamines. J. Chem. Soc., Perkin Trans. 2 0, 1125-1127. https://doi.org/10.1039/P29870001125

Erickson, R.E., Andrulis Jr, P.J., Collins, J.C., Lungle, M.L., Mercer, G.D., 1969. Mechanism of ozonation reactions. IV. Carbon-nitrogen double bonds. The Journal of Organic Chemistry 34, 2961-2966.

Flyunt, R., Leitzke, A., Mark, G., Mvula, E., Reisz, E., Schick, R., von Sonntag, C., 2003. Determination of $\bullet \mathrm{OH}, \mathrm{O} 2 \bullet-$, and Hydroperoxide Yields in Ozone Reactions in Aqueous Solution. The Journal of Physical Chemistry B 107, 7242-7253. https://doi.org/10.1021/jp022455b

Frisch, M.J., Trucks, G.W., Schlegel, H.B., Scuseria, G.E., Robb, M.A., Cheeseman, J.R., Scalmani, G., Barone, V., Petersson, G.A., Nakatsuji, H., Li, X., Caricato, M., Marenich, A., Bloino, J., Janesko, B.G., Gomperts, R., Mennucci, B., Hratchian, H.P., Ortiz, J.V., Izmaylov, A.F., Sonnenberg, J.L., Williams-Young, D., Ding, F., F. Lipparini, F. Egidi, J. Goings, B. Peng, A. Petrone, T. Henderson, D. Ranasinghe, V. G. Zakrzewski, J. Gao, N. Rega, G. Zheng, W. Liang, M. Hada, M. Ehara, K. Toyota, R. Fukuda, J. Hasegawa, M. Ishida, T. Nakajima, Y. Honda, O. Kitao, H. Nakai, T. Vreven, K. Throssell, J. A. Montgomery, Jr., J. E. Peralta, F. Ogliaro, M. Bearpark, J. J. Heyd, E. Brothers, K. N. Kudin, V. N. Staroverov, T. Keith, R. Kobayashi, J. Normand, K. Raghavachari, A. Rendell, J. C. Burant, S. S. Iyengar, J. Tomasi, M. Cossi, J. M. Millam, M. Klene, C. Adamo, R. Cammi, J. W. Ochterski, R. L. Martin, K. Morokuma, O. Farkas, J. B. Foresman, D. J. Fox, 2016. Gaussian 09, Revision D.01. Gaussian, Inc., Wallingford CT. 
Goldstein, S., Samuni, A., 2007. Kinetics and Mechanism of Peroxyl Radical Reactions with Nitroxides. The Journal of Physical Chemistry A 111, 1066-1072. https://doi.org/10.1021/jp0655975

Graeber, D., Boëchat, I.G., Encina-Montoya, F., Esse, C., Gelbrecht, J., Goyenola, G., Gücker, B., Heinz, M., Kronvang, B., Meerhoff, M., Nimptsch, J., Pusch, M.T., Silva, R.C.S., von Schiller, D., Zwirnmann, E., 2015. Global effects of agriculture on fluvial dissolved organic matter. Scientific Reports 5. https://doi.org/10.1038/srep16328

Hammes, F., Salhi, E., Köster, O., Kaiser, H.-P., Egli, T., von Gunten, U., 2006. Mechanistic and kinetic evaluation of organic disinfection by-product and assimilable organic carbon (AOC) formation during the ozonation of drinking water. Water Research 40, 2275-2286. https://doi.org/10.1016/j.watres.2006.04.029

Hariharan, P.C., Pople, J.A., 1973. The influence of polarization functions on molecular orbital hydrogenation energies. Theoretica Chimica Acta 28, 213-222. https://doi.org/10.1007/BF00533485

Hoigné, J., Bader, H., 1983. Rate constants of reactions of ozone with organic and inorganic compounds in water-II: dissociating organic compounds. Water Research 17, 185-194.

Hoigné, J., Bader, H., 1978. Ozonation of water: kinetics of oxidation of ammonia by ozone and hydroxyl radicals. Environmental Science \& Technology 12, 79-84.

Hoigné, J., Bader, H., Haag, W.R., Staehelin, J., 1985. Rate constants of reactions of ozone with organic and inorganic compounds in water-III. Inorganic compounds and radicals. Water Research 19, 993-1004. https://doi.org/10.1016/0043-1354(85)90368-9

Hübner, U., von Gunten, U., Jekel, M., 2015. Evaluation of the persistence of transformation products from ozonation of trace organic compounds - A critical review. Water Research 68, 150-170. https://doi.org/10.1016/j.watres.2014.09.051

Hwang, Y., Matsuo, T., Hanaki, K., Suzuki, N., 1995. Identification and quantification of sulfur and nitrogen containing odorous compounds in wastewater. Water Research 29, 711-718. https://doi.org/10.1016/0043-1354(94)00145-W

lanni, J.C., 2017. Kintecus.

Ingold, K.U., Adamic, K., Bowman, D.F., Gillan, T., 1971. Kinetic applications of electron paramagnetic resonance spectroscopy. I. Self-reactions of diethyl nitroxide radicals. Journal of the American Chemical Society 93, 902-908. https://doi.org/10.1021/ja00733a018

Jámbor, A., Molnár-Perl, I., 2009. Amino acid analysis by high-performance liquid chromatography after derivatization with 9-fluorenylmethyloxycarbonyl chloride. Journal of Chromatography A 1216, 3064-3077. https://doi.org/10.1016/j.chroma.2009.01.068

Johnson, D.H., Rogers, M.A.T., Trappe, G., 1956. 229. Aliphatic hydroxylamines. Part II. Autoxidation. Journal of the Chemical Society (Resumed) 0, 1093-1103. https://doi.org/10.1039/JR9560001093

Jonsson, M., Wayner, D.D.M., Lusztyk, J., 1996. Redox and Acidity Properties of Alkyl- and Arylamine Radical Cations and the Corresponding Aminyl Radicals ${ }^{1}$. The Journal of Physical Chemistry 100, 17539-17543. https://doi.org/10.1021/jp961286q

Knoop, O., Hohrenk, L.L., Lutze, H.V., Schmidt, T.C., 2018. Ozonation of tamoxifen and toremifeneReaction kinetics and transformation products. Environmental Science \& Technology 52, 1258312591. https://doi.org/10.1021/acs.est.8b00996

Krasner, S.W., Mitch, W.A., McCurry, D.L., Hanigan, D., Westerhoff, P., 2013. Formation, precursors, control, and occurrence of nitrosamines in drinking water: A review. Water Research 47, 44334450. https://doi.org/10.1016/j.watres.2013.04.050

Lange, F., Cornelissen, S., Kubac, D., Sein, M.M., von Sonntag, J., Hannich, C.B., Golloch, A., Heipieper, H.J., Möder, M., von Sonntag, C., 2006. Degradation of macrolide antibiotics by ozone: A 
mechanistic case study with clarithromycin. Chemosphere 65, 17-23. https://doi.org/10.1016/j.chemosphere.2006.03.014

Le Lacheur, R.M., Glaze, W.H., 1996. Reactions of ozone and hydroxyl radicals with serine. Environmental Science \& Technology 30, 1072-1080.

Lee, M., Blum, L.C., Schmid, E., Fenner, K., von Gunten, U., 2017. A computer-based prediction platform for the reaction of ozone with organic compounds in aqueous solution: kinetics and mechanisms. Environmental Science: Processes \& Impacts 19, 465-476. https://doi.org/10.1039/C6EM00584E

Lee, T.J., Taylor, P.R., 1989. A diagnostic for determining the quality of single-reference electron correlation methods. International Journal of Quantum Chemistry 36, 199-207. https://doi.org/10.1002/qua.560360824

Lee, Y., Escher, B.I., von Gunten, U., 2008. Efficient Removal of Estrogenic Activity during Oxidative Treatment of Waters Containing Steroid Estrogens. Environ. Sci. Technol. 42, 6333-6339. https://doi.org/10.1021/es7023302

Lee, Y., von Gunten, U., 2016. Advances in predicting organic contaminant abatement during ozonation of municipal wastewater effluent: reaction kinetics, transformation products, and changes of biological effects. Environmental Science: Water Research \& Technology 2, 421-442. https://doi.org/10.1039/C6EW00025H

Leitzke, A., Reisz, E., Flyunt, R., von Sonntag, C., 2001. The reactions of ozone with cinnamic acids: formation and decay of 2-hydroperoxy-2-hydroxyacetic acid. Journal of the Chemical Society, Perkin Transactions 2 793-797. https://doi.org/10.1039/b009327k

Lester, Y., Mamane, H., Zucker, I., Avisar, D., 2013. Treating wastewater from a pharmaceutical formulation facility by biological process and ozone. Water Research 47, 4349-4356. https://doi.org/10.1016/j.watres.2013.04.059

Leverenz, H.L., Tchobanoglous, G., Asano, T., 2011. Direct potable reuse: a future imperative. Journal of Water Reuse and Desalination 1, 2-10. https://doi.org/10.2166/wrd.2011.000

Lipari, F., Swarin, S.J., 1982. Determination of formaldehyde and other aldehydes in automobile exhaust with an improved 2, 4-dinitrophenylhydrazine method. Journal of Chromatography A 247, 297306.

Long, J.A., Harris, N.J., Lammertsma, K., 2001. Formaldehyde Oxime $\rightleftharpoons$ Nitrosomethane Tautomerism. The Journal of Organic Chemistry 66, 6762-6767. https://doi.org/10.1021/jo010671v

Magdeburg, A., Stalter, D., Schlüsener, M., Ternes, T., Oehlmann, J., 2014. Evaluating the efficiency of advanced wastewater treatment: Target analysis of organic contaminants and (geno-)toxicity assessment tell a different story. Water Research 50, 35-47. https://doi.org/10.1016/j.watres.2013.11.041

Marenich, A.V., Cramer, C.J., Truhlar, D.G., 2009. Universal Solvation Model Based on Solute Electron Density and on a Continuum Model of the Solvent Defined by the Bulk Dielectric Constant and Atomic Surface Tensions. The Journal of Physical Chemistry B 113, 6378-6396. https://doi.org/10.1021/jp810292n

Markofsky, S.B., 2011. Nitro Compounds, Aliphatic, in: Wiley-VCH Verlag GmbH \& Co. KGaA (Ed.), Ullmann's Encyclopedia of Industrial Chemistry. Wiley-VCH Verlag GmbH \& Co. KGaA, Weinheim, Germany. https://doi.org/10.1002/14356007.a17_401.pub2

McCurry, D.L., Quay, A.N., Mitch, W.A., 2016. Ozone Promotes Chloropicrin Formation by Oxidizing Amines to Nitro Compounds. Environmental Science \& Technology 50, 1209-1217. https://doi.org/10.1021/acs.est.5b04282

Mestankova, H., Escher, B., Schirmer, K., von Gunten, U., Canonica, S., 2011. Evolution of algal toxicity during (photo)oxidative degradation of diuron. Aquatic Toxicology 101, 466-473. https://doi.org/10.1016/j.aquatox.2010.10.012 
Mitch, W.A., Sedlak, D.L., 2004. Characterization and Fate of $N$-Nitrosodimethylamine Precursors in Municipal Wastewater Treatment Plants. Environmental Science \& Technology 38, 1445-1454. https://doi.org/10.1021/es035025n

Montgomery, J.A., Frisch, M.J., Ochterski, J.W., Petersson, G.A., 1999. A complete basis set model chemistry. VI. Use of density functional geometries and frequencies. The Journal of Chemical Physics 110, 2822-2827. https://doi.org/10.1063/1.477924

Muñoz, F., Mvula, E., Braslavsky, S.E., von Sonntag, C., 2001. Singlet dioxygen formation in ozone reactions in aqueous solution. Journal of the Chemical Society, Perkin Transactions 2 1109-1116. https://doi.org/10.1039/b101230o

Muñoz, F., von Sonntag, C., 2000a. The reactions of ozone with tertiary amines including the complexing agents nitrilotriacetic acid (NTA) and ethylenediaminetetraacetic acid (EDTA) in aqueous solution. Journal of the Chemical Society, Perkin Transactions 2 2029-2033. https://doi.org/10.1039/b004417m

Muñoz, F., von Sonntag, C., 2000b. Determination of fast ozone reactions in aqueous solution by competition kinetics. Journal of the Chemical Society, Perkin Transactions 2 661-664. https://doi.org/10.1039/a909668j

Murray, R.W., Jeyaraman, R., Mohan, L., 1986. A new synthesis of nitro compounds using dimethyldioxirane. Tetrahedron Letters 27, 2335-2336.

National Toxicology Program, 2016. Report on Carcinogens, Fourteenth Edition. U.S. Department of Health and Human Services, Public Health Service, Research Triangle Park, NC.

Naumov, S., von Sonntag, C., 2011. Standard Gibbs Free Energies of Reactions of Ozone with Free Radicals in Aqueous Solution: Quantum-Chemical Calculations. Environmental Science \& Technology 45, 9195-9204. https://doi.org/10.1021/es2018658

Nöthe, T., Fahlenkamp, H., von Sonntag, C., 2009. Ozonation of wastewater: rate of ozone consumption and hydroxyl radical yield. Environmental Science \& Technology 43, 5990-5995.

Olszyna, K., Heicklen, J., 1976. The inhibition of photochemical smog VI. The reaction of O3 with diethylhydroxylamine. Science of The Total Environment 5, 223-230. https://doi.org/10.1016/0048-9697(76)90074-7

Papajak, E., Zheng, J., Xu, X., Leverentz, H.R., Truhlar, D.G., 2011. Perspectives on Basis Sets Beautiful: Seasonal Plantings of Diffuse Basis Functions. Journal of Chemical Theory and Computation 7 , 3027-3034. https://doi.org/10.1021/ct200106a

Paradkar, V.M., Latham, T.B., Demko, D.M., 1995. Oxidative Decarboxylation of $\alpha$-Amino Acids with in situ Generated Dimethyl Dioxirane. Synlett 1059-1060. https://doi.org/10.1055/s-1995-5174

Pehlivanoglu-Mantas, E., Sedlak, D.L., 2006. Wastewater-Derived Dissolved Organic Nitrogen: Analytical Methods, Characterization, and Effects-A Review. Critical Reviews in Environmental Science and Technology 36, 261-285. https://doi.org/10.1080/10643380500542780

Pryor, W.A., Giamalva, D.H., Church, D.F., 1984. Kinetics of ozonation. 2. Amino acids and model compounds in water and comparisons to rates in nonpolar solvents. Journal of the American Chemical Society 106, 7094-7100. https://doi.org/10.1021/ja00335a038

Raghavachari, K., Trucks, G.W., Pople, J.A., Head-Gordon, M., 1989. A fifth-order perturbation comparison of electron correlation theories. Chemical Physics Letters 157, 479-483. https://doi.org/10.1016/S0009-2614(89)87395-6

Ramseier, M.K., Peter, A., Traber, J., von Gunten, U., 2011. Formation of assimilable organic carbon during oxidation of natural waters with ozone, chlorine dioxide, chlorine, permanganate, and ferrate. Water Research 45, 2002-2010. https://doi.org/10.1016/j.watres.2010.12.002

Riebel, A.H., Erickson, R.E., Abshire, C.J., Bailey, P.S., 1960. Ozonation of Carbon-Nitrogen Double Bonds. I. Nucleophilic Attack of Ozone ${ }^{1}$. Journal of the American Chemical Society 82, 1801-1807. https://doi.org/10.1021/ja01492a062 
Rios, A., Amyes, T.L., Richard, J.P., 2000. Formation and Stability of Organic Zwitterions in Aqueous Solution: Enolates of the Amino Acid Glycine and Its Derivatives. Journal of the American Chemical Society 122, 9373-9385. https://doi.org/10.1021/ja001749c

Roca-López, D., Tejero, T., Caramella, P., Merino, P., 2014. [2n2 $\pi+2 n 2 \pi]$ Cycloadditions: an alternative to forbidden $[4 \pi+4 \pi]$ processes. The case of nitrone dimerization. Organic \& Biomolecular Chemistry 12, 517-525. https://doi.org/10.1039/С30B42014K

Sacher, F., Lenz, S., Brauch, H.-J., 1997. Analysis of primary and secondary aliphatic amines in waste water and surface water by gas chromatography-mass spectrometry after derivatization with 2 , 4-dinitrofluorobenzene or benzenesulfonyl chloride. Journal of Chromatography A 764, 85-93.

Sander, R., 2015. Compilation of Henry's law constants (version 4.0) for water as solvent. Atmospheric Chemistry and Physics 15, 4399-4981.

Sein, M.M., Zedda, M., Tuerk, J., Schmidt, T.C., Golloch, A., Sonntag, C. von, 2008. Oxidation of Diclofenac with Ozone in Aqueous Solution. Environmental Science \& Technology 42, 6656-6662. https://doi.org/10.1021/es8008612

Shah, A.D., Mitch, W.A., 2012. Halonitroalkanes, halonitriles, haloamides, and N-nitrosamines: a critical review of nitrogenous disinfection byproduct formation pathways. Environmental Science \& Technology 46, 119-131. https://doi.org/10.1021/es203312s

Smith, G.G., Sivakua, T., 1983. Mechanism of the racemization of amino acids. Kinetics of racemization of arylglycines. The Journal of Organic Chemistry 48, 627-634. https://doi.org/10.1021/jo00153a001

Stalter, D., Magdeburg, A., Weil, M., Knacker, T., Oehlmann, J., 2010. Toxication or detoxication? In vivo toxicity assessment of ozonation as advanced wastewater treatment with the rainbow trout. Water Research 44, 439-448. https://doi.org/10.1016/j.watres.2009.07.025

Tekle-Röttering, A., Jewell, K.S., Reisz, E., Lutze, H.V., Ternes, T.A., Schmidt, W., Schmidt, T.C., 2016. Ozonation of piperidine, piperazine and morpholine: Kinetics, stoichiometry, product formation and mechanistic considerations. Water Research 88, 960-971. https://doi.org/10.1016/j.watres.2015.11.027

Tentscher, P.R., Bourgin, M., von Gunten, U., 2018. Ozonation of Para -Substituted Phenolic Compounds Yields $p$-Benzoquinones, Other Cyclic $\alpha, \beta$-Unsaturated Ketones, and Substituted Catechols. Environmental Science \& Technology 52, 4763-4773. https://doi.org/10.1021/acs.est.8b00011

Ternes, T.A., Stüber, J., Herrmann, N., McDowell, D., Ried, A., Kampmann, M., Teiser, B., 2003. Ozonation: a tool for removal of pharmaceuticals, contrast media and musk fragrances from wastewater? Water Research 37, 1976-1982. https://doi.org/10.1016/S0043-1354(02)00570-5

Trogolo, D., Arey, J.S., Tentscher, P.R., 2019. Gas-Phase Ozone Reactions with a Structurally Diverse Set of Molecules: Barrier Heights and Reaction Energies Evaluated by Coupled Cluster and Density Functional Theory Calculations. The Journal of Physical Chemistry A. https://doi.org/10.1021/acs.jpca.8b10323

USEPA, 1985. Health and environmental effects profile for nitromethane (No. EPA/600/X-85/116 (NTIS PB88180518)). U.S. Environmental Protection Agency, Washington, D.C.

von Gunten, U., 2018. Oxidation Processes in Water Treatment: Are We on Track? Environmental Science \& Technology 52, 5062-5075. https://doi.org/10.1021/acs.est.8b00586

von Gunten, U., 2003. Ozonation of drinking water: Part I. Oxidation kinetics and product formation. Water Research 37, 1443-1467. https://doi.org/10.1016/S0043-1354(02)00457-8

von Sonntag, C., von Gunten, U., 2012. Chemistry of Ozone in Water and Wastewater Treatment. IWA Publishing.

Wardman, P., 1989. Reduction Potentials of One-Electron Couples Involving Free Radicals in Aqueous Solution. Journal of Physical and Chemical Reference Data 18, 1637-1755. https://doi.org/10.1063/1.555843 
Wayne, R.P., Pitts, J.N., 1969. Rate Constant for the Reaction O2 $(1 \Delta \mathrm{g})+\mathrm{O} 3 \rightarrow 2 \mathrm{O} 2+\mathrm{O}$. The Journal of Chemical Physics 50, 3644-3645. https://doi.org/10.1063/1.1671606

Westerhoff, P., Mash, H., 2002. Dissolved organic nitrogen in drinking water supplies: a review. Journal of Water Supply: Research and Technology-AQUA 51, 415-448. https://doi.org/10.2166/aqua.2002.0038

WHO, 2005. Trihalomethanes in drinking-water. Background document for development of WHO Guidelines for drinking-water quality (No. WHO/SDE/WSH/05.08/64). World Health Organization, Geneva.

Yang, L., Chen, Z., Shen, J., Xu, Z., Liang, H., Tian, J., Ben, Y., Zhai, X., Shi, W., Li, G., 2009. Reinvestigation of the Nitrosamine-Formation Mechanism during Ozonation. Environmental Science \& Technology 43, 5481-5487. https://doi.org/10.1021/es900319f

Zhao, Y., Truhlar, D.G., 2008. The M06 suite of density functionals for main group thermochemistry, thermochemical kinetics, noncovalent interactions, excited states, and transition elements: two new functionals and systematic testing of four M06-class functionals and 12 other functionals. Theoretical Chemistry Accounts 120, 215-241. https://doi.org/10.1007/s00214-007-0310-x

Zimmermann, S.G., Schmukat, A., Schulz, M., Benner, J., von Gunten, U., Ternes, T.A., 2012. Kinetic and Mechanistic Investigations of the Oxidation of Tramadol by Ferrate and Ozone. Environmental Science \& Technology 46, 876-884. https://doi.org/10.1021/es203348q

Zubarev, V., Brede, O., 1994. Direct Detection of the Cation Radical of the Spin Trap a-Phenyl-N-tertbutylnitrone. Journal of the Chemical Society, Perkin Transactions 2 0, 1821-1828. 
971 Table 1. Species-specific and apparent second-order rate constants for the reactions of the selected

972 amines with ozone and $\mathrm{p} K_{\mathrm{a}}$ values of the amines.

\begin{tabular}{|c|c|c|c|c|c|c|}
\hline Compound & $\mathrm{p} K_{\mathrm{a}}$ & Method $^{c}$ & $\mathrm{pH}^{\mathrm{d}}$ & $k, \mathrm{M}^{-1} \mathrm{~s}^{-1}$ & $\begin{array}{l}k_{\mathrm{obs}, \mathrm{pH}}, \\
\mathrm{M}^{-1} \mathrm{~s}^{-1}\end{array}$ & Reference \\
\hline Ethylamine & 10.6 & Indigo & $5.0-7.0$ & $\begin{array}{l}(9.3 \pm 0.1) \times 10^{4} \\
2.4 \times 10^{5}\end{array}$ & 21 & $\begin{array}{l}\text { This study } \\
\text { (Muñoz and von } \\
\text { Sonntag, 2000a) } \\
\end{array}$ \\
\hline Diethylamine & 10.5 & Indigo & $3.0-7.0$ & $\begin{array}{l}(3.9 \pm 0.1) \times 10^{5} \\
6.2 \times 10^{5} \\
9.1 \times 10^{5}\end{array}$ & $1.3 \times 10^{2}$ & $\begin{array}{l}\text { This study } \\
\text { (Pryor et al., 1984) } \\
\text { (Muñoz and von } \\
\text { Sonntag, 2000a) }\end{array}$ \\
\hline Triethylamine & 11.0 & Indigo & $4.0-6.5$ & $\begin{array}{l}(2.2 \pm 0.1) \times 10^{6} \\
2.1 \times 10^{6} \\
4.1 \times 10^{6}\end{array}$ & $2.2 \times 10^{2}$ & $\begin{array}{l}\text { This study } \\
\text { (Pryor et al., 1984) } \\
\text { (Muñoz and von } \\
\text { Sonntag, 2000a) }\end{array}$ \\
\hline $\begin{array}{l}\mathrm{N}, \mathrm{N} \text {-Diethyl- } \\
\text { hydroxylamine }\end{array}$ & $5.4^{\mathrm{a}}$ & $\begin{array}{l}\text { Indigo; } \\
\text { CK }\end{array}$ & $1.6-8.0$ & $\begin{array}{l}(7.0 \pm 0.02) \\
\times 10^{5}\end{array}$ & $6.8 \times 10^{5}$ & This study \\
\hline $\begin{array}{l}N \text {-ethyl- } \\
\text { hydroxylamine }\end{array}$ & $6.2^{b}$ & Indigo & 2 and 4 & ND & $\sim 10^{5}$ & This study \\
\hline $\begin{array}{l}\text {-ethyl- } \\
\text { ethanimine } \\
\text { oxide }\end{array}$ & NA & Indigo & 7.0 only & ND & $\begin{array}{l}(1.9 \pm 0.04) \\
\times 10^{3}\end{array}$ & This study \\
\hline Nitroethane & NA & Indigo & 7.0 only & ND & $3.4 \pm 0.1$ & This study \\
\hline
\end{tabular}

${ }^{\mathrm{a}} \mathrm{p} K_{\mathrm{a}}$ of $\mathrm{N}, \mathrm{N}$-diethylhydroxylamine was estimated from the apparent second-order rate constants

974 measured at varying $\mathrm{pH}$ conditions (see the fitting equation and the result in Text S2 and Figure $\mathrm{S} 2$ ). ${ }^{\mathrm{b}} \mathrm{p} K_{\mathrm{a}}$

975 of $N$-ethylhydroxylamine was predicted by a commercial software (ACD/Labs, V11.02)

976 (https://www.acdlabs.com). ${ }^{c}$ Reaction kinetics were determined by direct monitoring of the ozone

977 decrease with the indigo method (indigo) or by competition kinetics with cinnamic acid (CK) as described

978 in detail in Text S2. ${ }^{\mathrm{d}}$ Experimental $\mathrm{pH}$ range. 

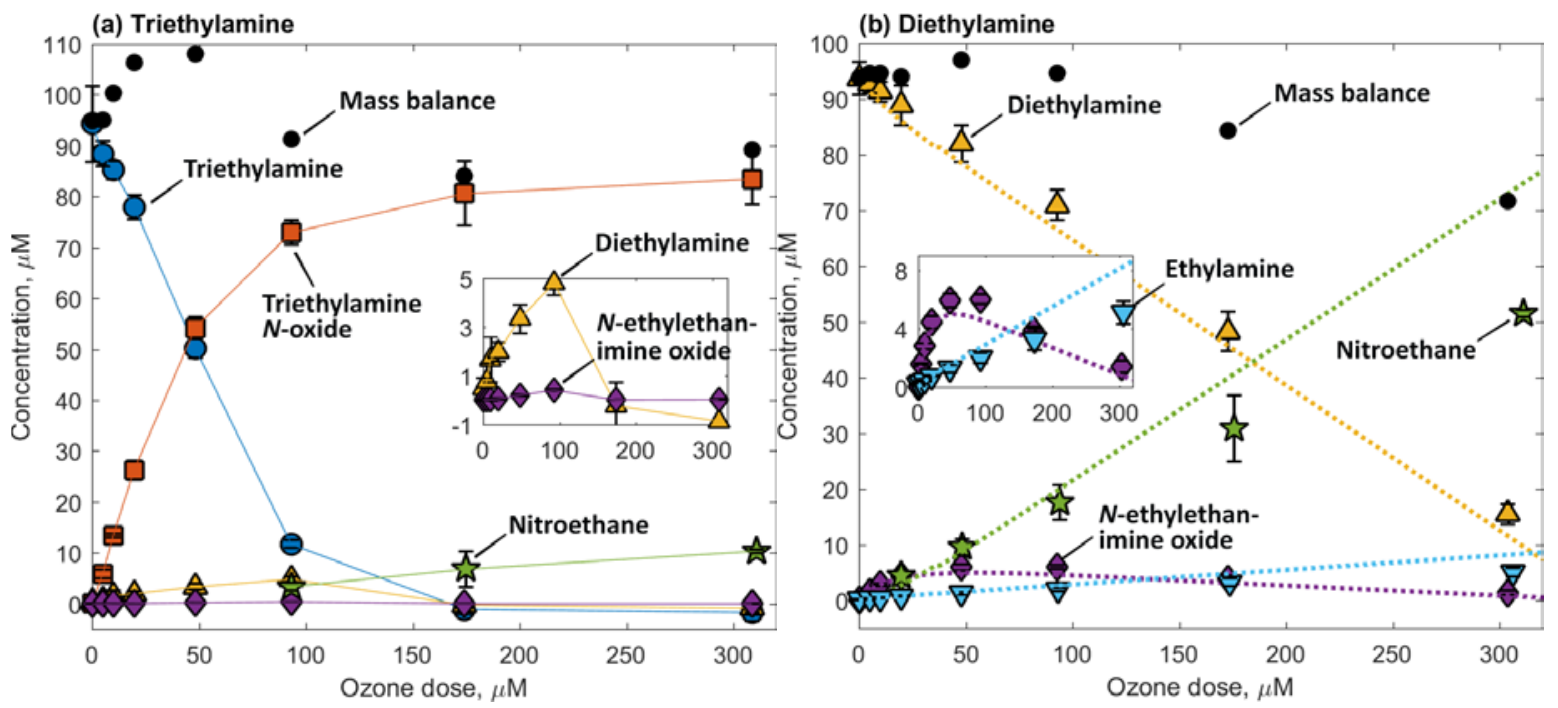

(c) N,N-diethylhydroxylamine
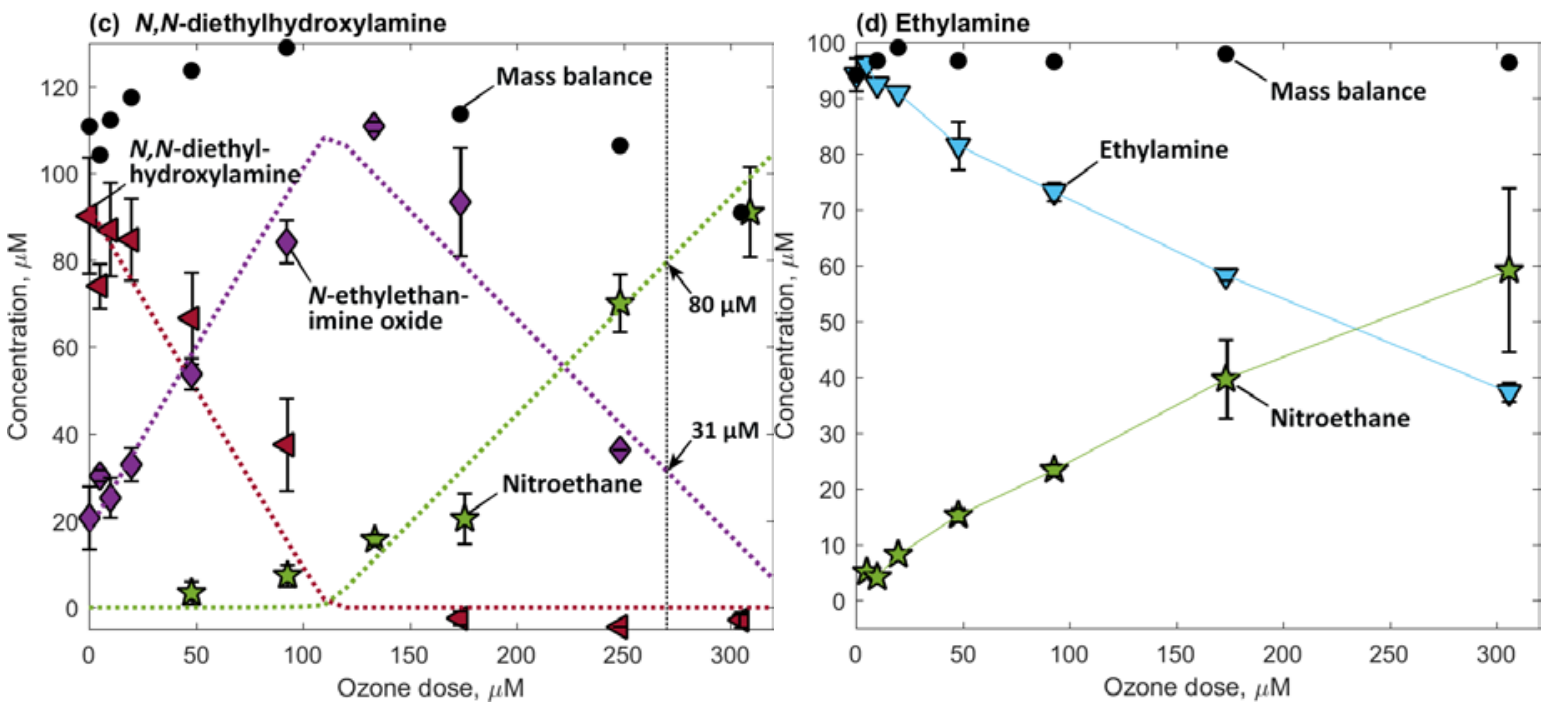

981

Figure 1. Evolution of the amine model compounds and transformation products as a function of the

ozone doses for the reactions of ozone with (a) triethylamine, (b) diethylamine, (c) $\mathrm{N}, \mathrm{N}$ -

diethylhydroxylamine, and (d) ethylamine. Inserts in (a) and (b) have the same axis labels as the main

plots. The symbols indicate measured concentrations (duplicate or triplicate) and the dotted lines in (b) and (c) indicate simulated concentrations based on the kinetic models described in Table S7 and Table

S5, respectively. The vertical line in (c) is at an ozone dose of $270 \mu \mathrm{M}$. The errors were calculated as 
$\mathrm{mM}, 10 \mathrm{mM}$ phosphate buffer $(\mathrm{pH} 7)$, and reaction time $=24 \mathrm{~h}$ (triethylamine, diethylamine, and ethylamine) or $3-5 \mathrm{~h}(\mathrm{~N}, \mathrm{~N}$-diethylhydroxylamine).

991 Table 2. Yields of reactive oxygen species $\left({ }^{1} \mathrm{O}_{2}\right.$ and $\left.\bullet \mathrm{OH}\right)$ per consumed ozone at an amine:ozone ratio of 992 1:1 (yields for other ratios are given in Table S3 and Figure S12). Ozone concentrations were 0.1 or $0.4-$ $9930.5 \mathrm{mM}$ for ${ }^{1} \mathrm{O}_{2}$ measurements and $0.09 \mathrm{mM}$ for $\bullet \mathrm{OH}$ measurements. All measurements were performed 994 at $\mathrm{pH}$ 7, except for ${ }^{1} \mathrm{O}_{2}$ formation from ethylamine (pH 9). $t$-Butanol was added for all ${ }^{1} \mathrm{O}_{2}$ measurements 995 carried out in this study. Yields were averaged for 5-9 replicates for ${ }^{1} \mathrm{O}_{2}$ and duplicates for $\bullet \mathrm{OH}$ and standard deviations were within $10 \%$ of the average values.

\begin{tabular}{|l|l|l|l|l|l|}
\hline Compound & Type & ${ }^{1} \mathrm{O}_{2} / \mathrm{O}_{3}$ & Reference & $\bullet \mathrm{OH} / \mathrm{O}_{3}$ & Reference \\
\hline Triethylamine & Tertiary amine & $\begin{array}{l}0.70 \\
0.80^{\mathrm{a}}\end{array}$ & $\begin{array}{l}\text { This study } \\
\text { (Muñoz et al., 2001) }\end{array}$ & $\begin{array}{l}0.064 \\
0.15\end{array}$ & $\begin{array}{l}\text { This study } \\
\text { (Flyunt et al., 2003) }\end{array}$ \\
\hline Diethylamine & $\begin{array}{l}\text { Secondary } \\
\text { amine }\end{array}$ & 0.46 & This study & 0.26 & This study \\
\hline $\begin{array}{l}\text { Glycine } \\
\text { Ethylamine }\end{array}$ & Primary amine & $\begin{array}{l}0.20^{\mathrm{b}} \\
0.17^{\mathrm{b}}\end{array}$ & $\begin{array}{l}\text { (Muñoz et al., 2001) } \\
\text { (Muñoz et al., 2001) }\end{array}$ & 0.28 & $\begin{array}{l}\text { (Tekle-Röttering et } \\
\text { al., 2016) }\end{array}$ \\
\hline $\begin{array}{l}\mathrm{N}, \mathrm{N} \text {-diethyl- } \\
\text { hydroxylamine }\end{array}$ & Hydroxylamine & 0.38 & This study & 0.43 & $\begin{array}{l}\text { This study } \\
\text { (de Vera et al., } \\
\text { 2017) }\end{array}$ \\
\hline $\begin{array}{l}N \text {-ethylethan- } \\
\text { imine oxide }\end{array}$ & Nitrone & $0.43^{\mathrm{c}}$ & This study & $0.43^{\mathrm{c}}$ & This study \\
\hline
\end{tabular}

998 amine:ozone $=10 ;{ }^{c}$ possibly influenced by the presence of a dimer. 


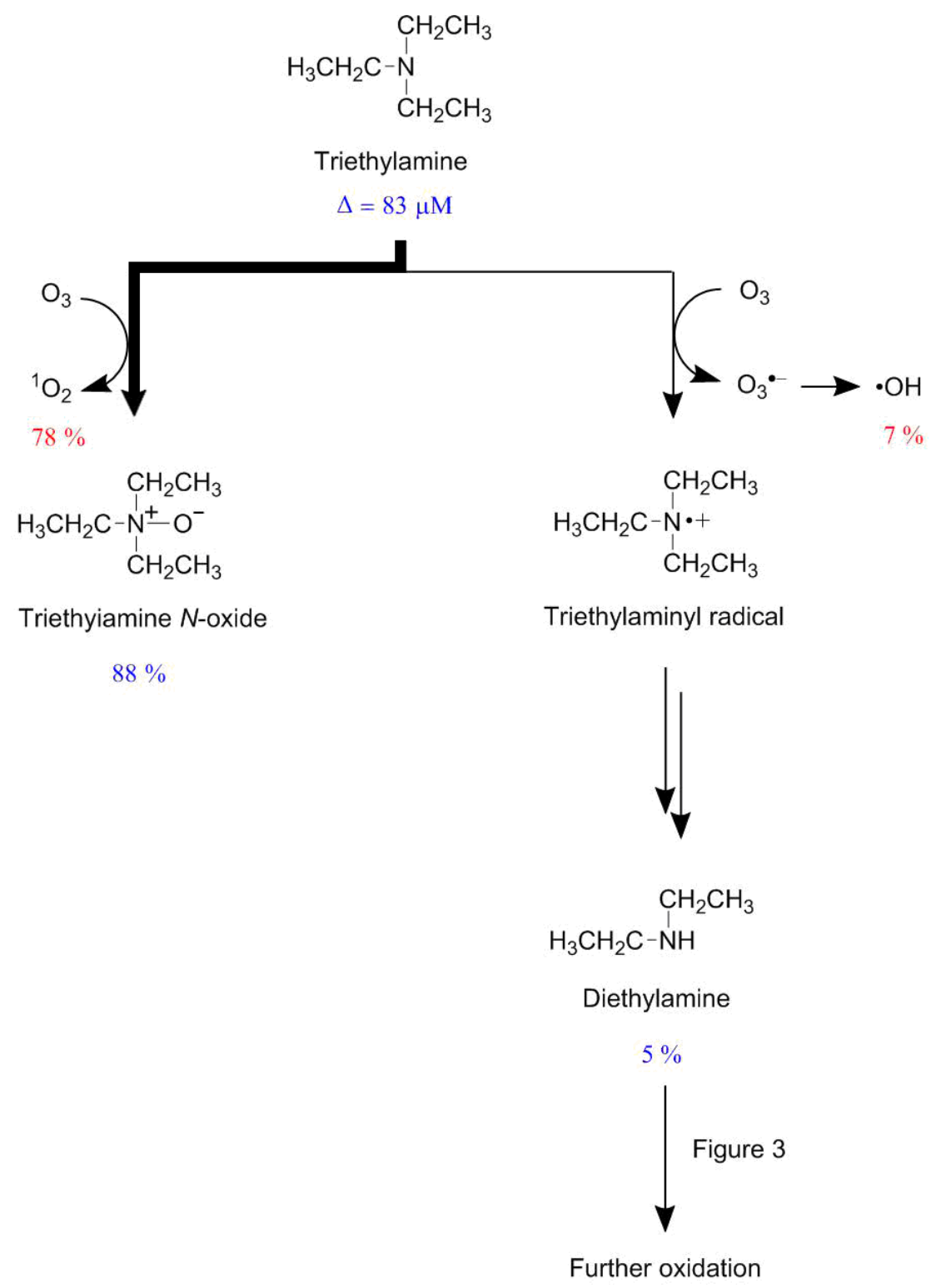

1000 Figure 2. Proposed mechanism for the reaction of triethylamine with ozone. Product yields (in \%) were 1001 calculated by dividing the measured concentrations of the transformation products and the reactive 1002 oxygen species by the abated triethylamine $(83 \mu \mathrm{M})$ at an ozone dose of $93 \mu \mathrm{M}$. The bold arrow 1003 indicates the major pathway of the branched reaction. 


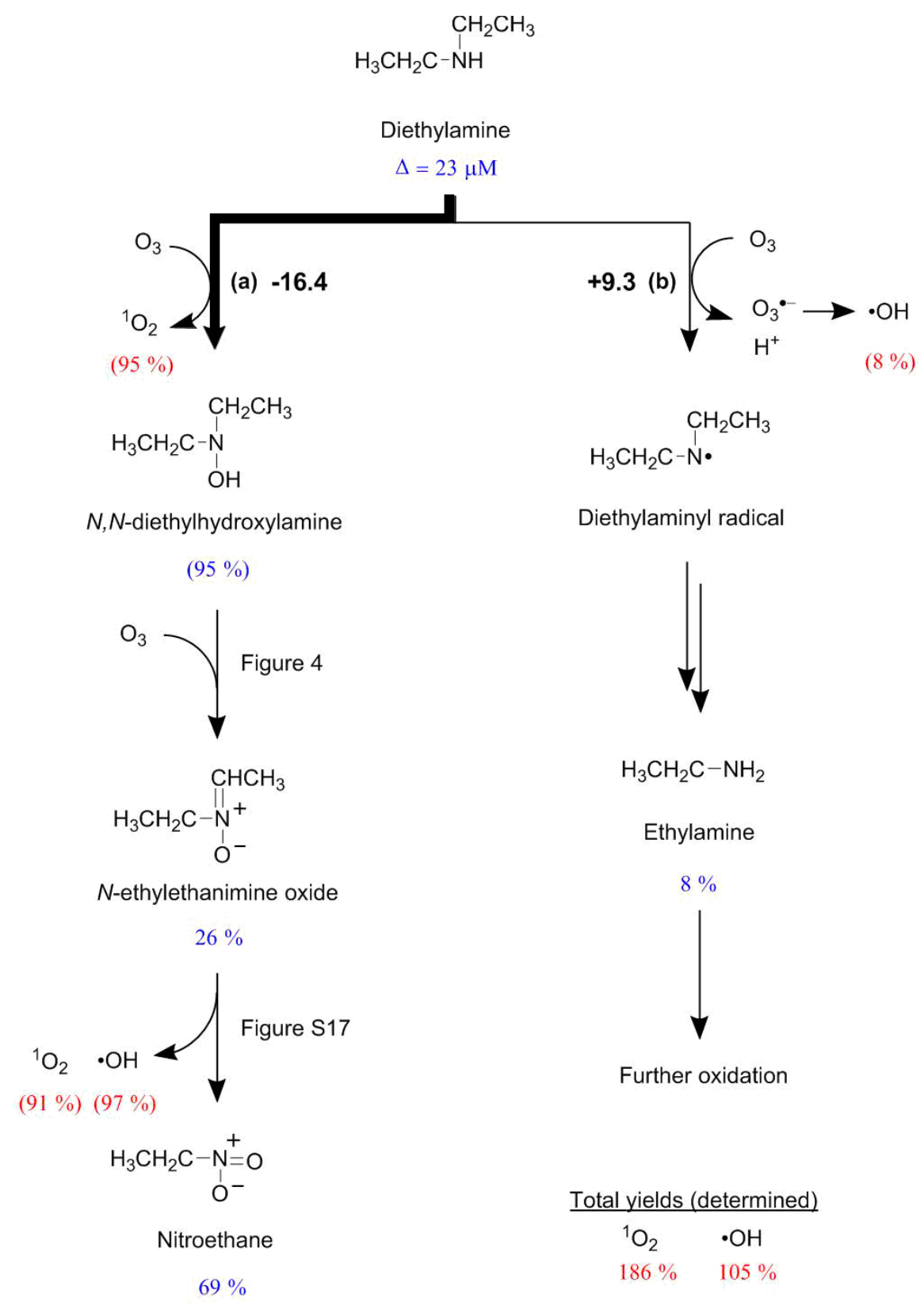

1004

1005 Figure 3. Proposed mechanism for the reaction of diethylamine with ozone. Product yields (in \%) were 1006 calculated by dividing the measured concentrations of the transformation products and the reactive 1007 oxygen species by the abated diethylamine $(23 \mu \mathrm{M})$ at an ozone dose of $93 \mu \mathrm{M}$. The yield of $N, N$ -

1008 diethylhydroxylamine in parenthesis is a theoretical yield based on the sum of the $N$-ethylethanimine 1009 oxide and nitroethane yields. The ${ }^{1} \mathrm{O}_{2}$ and $\bullet \mathrm{OH}$ yields in parentheses are also theoretical yields based on 1010 the yields of the corresponding transformation products and the total ${ }^{1} \mathrm{O}_{2}$ and $\bullet \mathrm{OH}$ yields determined 
1011 for the diethylamine-ozone reaction $\left(186 \%{ }^{1} \mathrm{O}_{2}\right.$ and $\left.105 \% \bullet \mathrm{OH}\right)$. Bold numbers next to the reaction 1012 steps are calculated aqueous Gibbs free energies in $\mathrm{kcal} \mathrm{mol}^{-1}$. The bold arrow indicates the major 1013 pathway of the branched reaction.

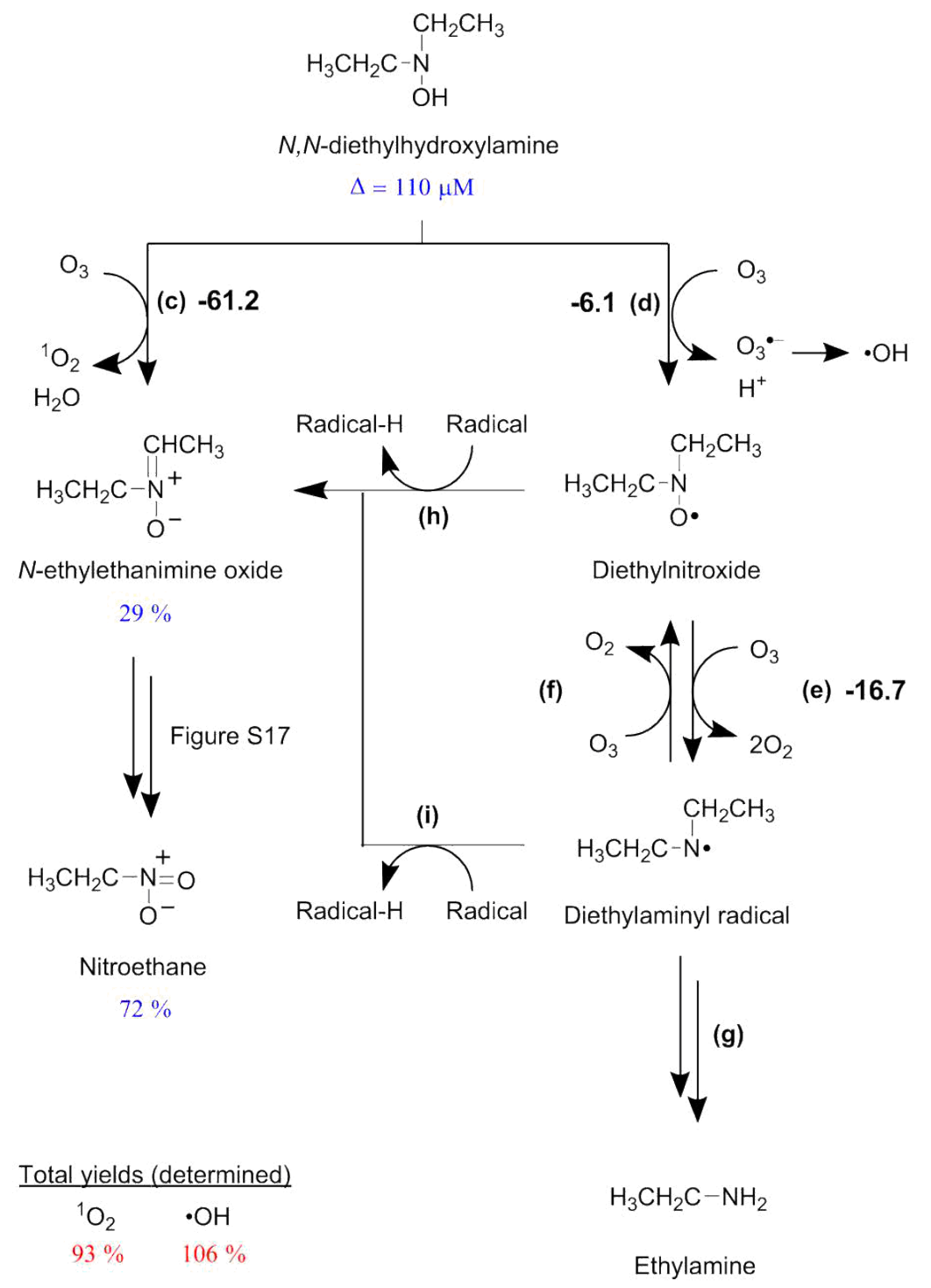

1015 Figure 4. Proposed mechanism for the reaction of $N, N$-diethylhydroxylamine and $N$-ethylethanimine 1016 oxide with ozone. Product yields (in \%) were calculated by dividing the simulated concentrations of the 1017 transformation products and the measured concentrations of reactive oxygen species by the abated $1018 \mathrm{~N}, \mathrm{~N}$-diethylhydroxylamine $(110 \mu \mathrm{M})$ at an ozone dose of $270 \mu \mathrm{M}$. Bold numbers next to the reaction 
1019 steps are calculated aqueous Gibbs free energies in $\mathrm{kcal} \mathrm{mol}^{-1}$. For discussion of reactions (c) - (i) see 1020 text.

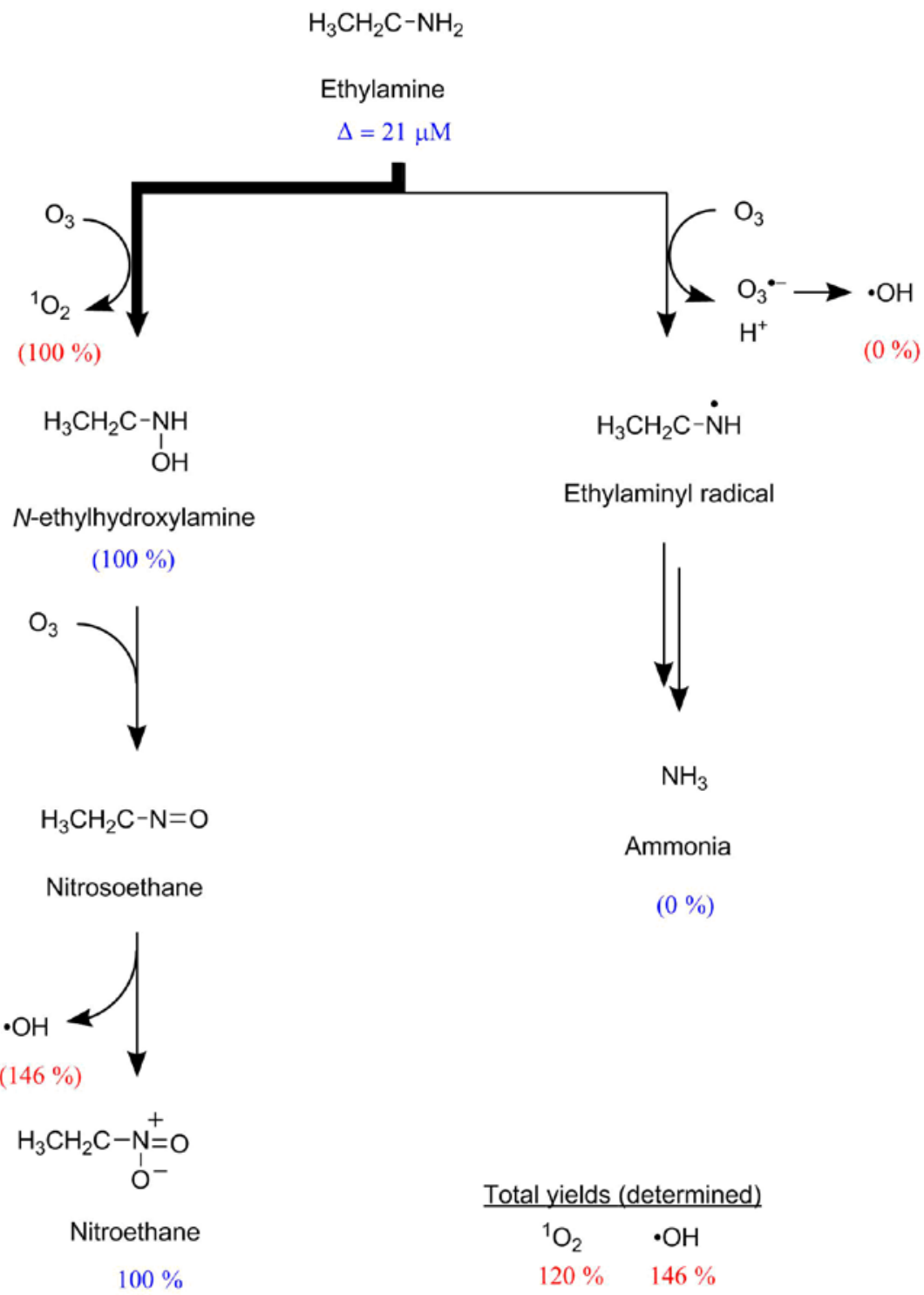

1022 Figure 5. Proposed mechanism for the reaction of ethylamine with ozone. Product yields (in \%) were

1023 calculated by dividing the measured concentrations of the transformation products and the reactive 1024 oxygen species by the abated ethylamine $(21 \mu \mathrm{M})$ at an ozone dose of $93 \mu \mathrm{M}$. The yield of $N$ -

1025 ethylhydroxylamine in parenthesis is a theoretical yield based on the nitroethane yield. The ${ }^{1} \mathrm{O}_{2}$ and $\bullet \mathrm{OH}$ 1026 yields in parentheses are also theoretical yields based on the yields of the corresponding transformation 
1027 products and the total ${ }^{1} \mathrm{O}_{2}$ and $\bullet \mathrm{OH}$ yields determined for the ethylamine-ozone reaction $\left(120 \%{ }^{1} \mathrm{O}_{2}\right.$ and $1028146 \% \bullet \mathrm{OH})$. The bold arrow indicates the major pathway of the branched reaction.

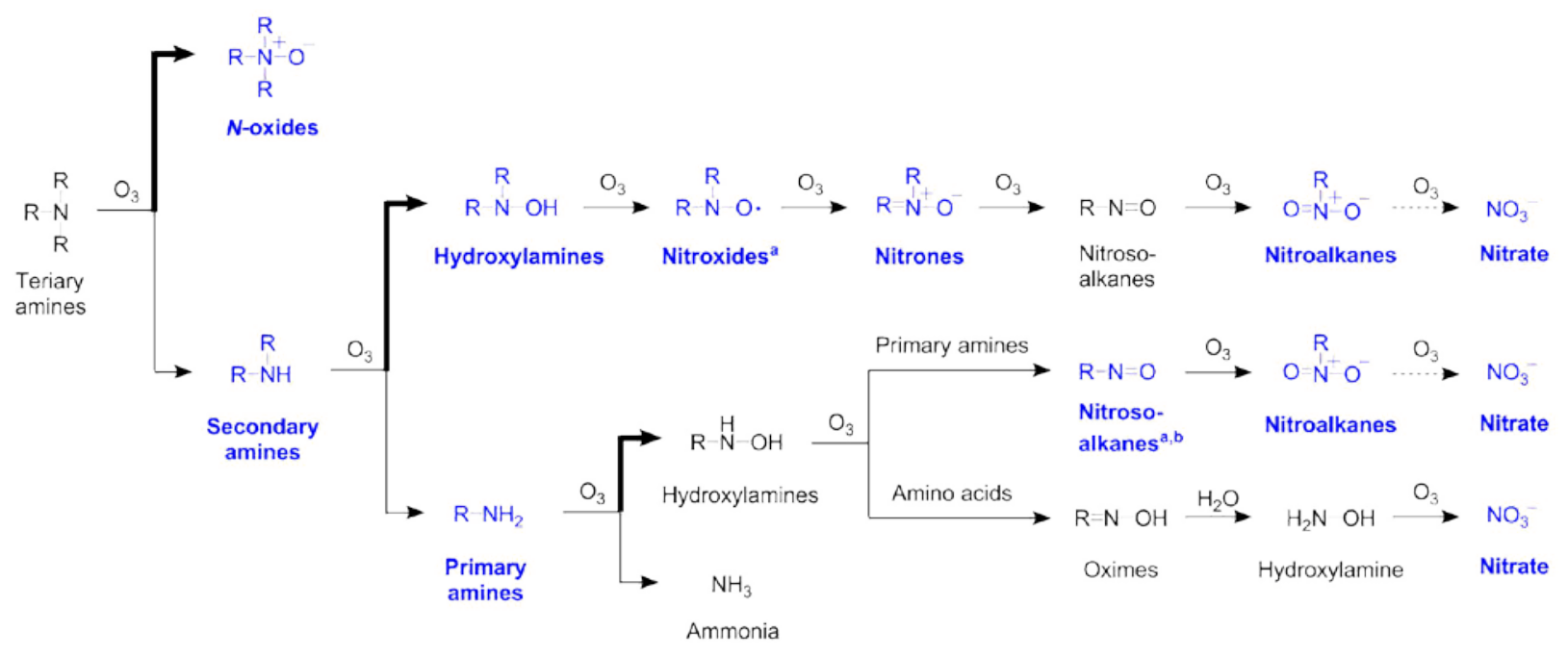

1030

1031

1032

1033

1034

1035

1036

1037

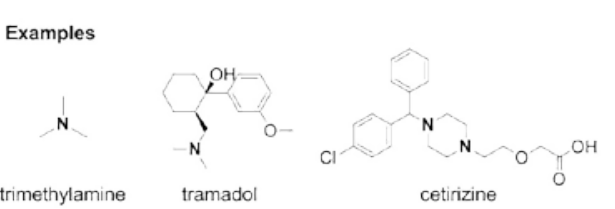

trimethylamine tramadol

Tertiary amines

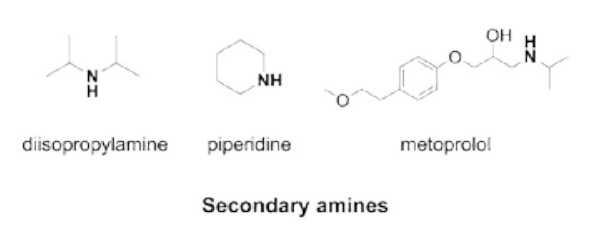

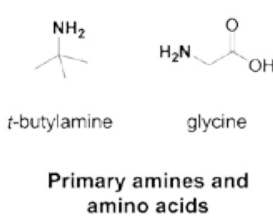

Figure 6. Summary of the reactions of aliphatic primary, secondary, and tertiary amines with ozone in aqueous solution based on this and other studies (both acyclic and saturated heterocyclic amines as shown in the examples) (Bailey et al., 1978; Bailey and Keller, 1968; Benner and Ternes, 2009b; Berger et al., 1999; Borowska et al., 2016; de Vera et al., 2017; Muñoz and von Sonntag, 2000a; Tekle-Röttering et al., 2016, p.; Zimmermann et al., 2012). Bold arrows indicate the dominant pathway. Identified

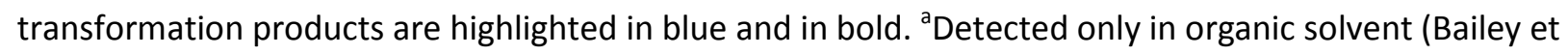
al., 1978). ' Indirectly confirmed based on a change in color of the solution (Bailey and Keller, 1968). 